\title{
NUEVA ORDENACIÓN TAXONÓMICA DEL SUBGÉNERO ELONGASIDA ESCALERA, 1906 DEL GÉNERO ALPHASIDA ESCALERA, 1905 (COLEOPTERA, TENEBRIONIDAE)
}

\author{
Francisco Pérez-Vera ${ }^{*}$, José M. Ávila² \& Juan Carlos Martínez ${ }^{3}$ \\ ' Departamento de Zoología, Universidad de Granada, E - 18071, España. e-mail: fperezvera@yahoo.fr \\ ORCID iD: http://orcid.org/0000-0002-2781-1618 \\ ${ }^{2}$ Departamento de Zoología, Universidad de Granada, E - 18071, España. e-mail: jmavila@ugr.es \\ ORCID iD: http://orcid.org/0000-0003-3785-4379
}

${ }_{3}^{3}$ Departamento de Zoología y Antropología Física. Área de Biología Animal. Facultad de Veterinaria. Universidad de Murcia, 30100 Murcia, España. e-mail: juanchismf@hotmail.com - ORCID iD: http://orcid.org/0000-0001-5931-255X

* Autor para correspondencia

\section{RESUMEN}

Como consecuencia de nuestra actual remodelación taxonómica de la tribu Asidini, la composición específica y la posición sistemática de los subgéneros Elongasida Escalera, 1906 y Pseudoelongasida Escalera, 1922, habían ya cambiado en relación con lo señalado en el último Catalogue of Palaearctic Coleoptera de Löbl \& Smetana. El subgénero Elongasida ha perdido las especies $A$. asperata Solier, 1836 y $A$. inesperata Escalera, 1921 incorporadas al subgénero Glabrasida y el subgénero Pseudoelongasida ha pasado de ser un subgénero del género Asida a ser un subgénero del género Alphasida, recuperando como válida la especie $A$. tenuecostata Fairmaire, 1880 que había sido considerada antes incertae sedis. En este trabajo se hace una revisión de los dos subgéneros y se propone la fusión de ambos en el único subgénero Elongasida, que se convertiría así en ibérico-marroquí. Pseudoelongasida pasa a ser nova synonymia y el nuevo subgénero resultante de la fusión cuenta con 12 especies: las 2 norteafricanas, las 8 ibéricas ya conocidas y 2 especies nuevas descritas aquí, conservadas como nomen in litteris en las colecciones del MNCN de Madrid: Alphasida (Elongasida) levantina sp. nov. y Alphasida (Elongasida) moroderi sp. nov.

http://zoobank.org/urn:Isid:zoobank.org:pub:837DA75B-EC1F-4573-8FDD-21604D2BB934

Palabras clave: Coleoptera; Tenebrionidae; Asidini; Asida; Alphasida; Elongasida; Pseudoelongasida; Alphasida levantina; Alphasida moroderi; Marruecos; España.

\section{ABSTRACT}

New taxonomic arrangement of the subgenus Elongasida Escalera, 1906 of the genus Alphasida Escalera, 1905 (Coleoptera, Tenebrionidae)

As a consequence of our current taxonomic remodeling of the Asidini tribe we are doing, the specific composition and systematic position of the subgenres Elongasida Escalera, 1906 and Pseudoelongasida Escalera, 1922, they had already changed in relation to what was pointed out in the last Catalogue of Palaearctic Coleoptera from Löbl \& Smetana. Elongasida has lost the species $A$. asperata Solier, 1836 and $A$. inesperata Escalera, 1921 incorporated to subgenre Glabrasida and subgenre Pseudoelongasida has gone from being a subgenre of genre Asida to be a subgenre of genre Alphasida, recovering like valid the species $A$. tenuecostata Fairmaire, 1880 that had been previously considered incertae sedis. In this work a revision of the two subgenera is made and it is proposed the fusion of both in the unique subgenre Elongasida that would become lberianMoroccan. Pseudoelongasida becomes a new synonymia and the new subgenus resulting from the fusion has twelve species: two North Africans, eight lberians already known and two new species described here, preserved as nomen in litteris in the collections of MNCN of Madrid: Alphasida (Elongasida) levantina sp. nov. and Alphasida (Elongasida) moroderi sp. nov.

Key words: Coleoptera; Tenebrionidae; Asidini; Asida; Alphasida; Elongasida; Pseudoelongasida; Alphasida levantina; Alphasida moroderi; Morocco; Spain. 
Cómo citar este artículo/Citation: Pérez-Vera, F., Ávila, J. M. \& Martínez, J. C. 2017. Nueva ordenación taxonómica del subgénero Elongasida Escalera, 1906 del género Alphasida Escalera, 1905 (Coleoptera, Tenebrionidae). Graellsia, 73(2): e062. http://dx.doi.org/10.3989/graellsia.2017.v73.183

Copyright: (C) 2017 SAM y CSIC. This is an open-access article distributed under the terms of the Creative Commons Attribution (CC-by) Spain 3.0 License.

\section{Introducción}

La tribu Asidini, creada por John Fleming (Fleming, 1821: 41) y rebautizada como tribu 'des Asidites' por Antoine Joseph Jean Solier (Solier, 1836: 403), estuvo durante largo tiempo representada en la región Paleártica por el único género Asida Latreille, 1802 (Latreille, 1802: 233), como lo confirman los trabajos del propio Solier y algo más tarde de Ernest Allard (Allard, 1869: 161). Cuando M. Martínez de la Escalera, a principios del siglo XX, inició su Sistema del género Asida en la Península Ibérica y en Marruecos, estableció un cierto número de subgéneros con la intención de facilitar la ordenación taxonómica de las numerosas especies ya conocidas y de las nuevas que él iba encontrando. El subgénero Elongasida, fue creado en 1906 (Escalera, 1906: 306) sobre ocho especies de las cuales cuatro eran ya conocidas: Asida alonensis (Martínez \& Sáez, 1863), A. asperata (Solier, 1836), A. grandipalpis (Allard, 1869) y A. hesperica (Rambur, 1838) y otras cuatro que se agregaban como nuevas: A. calumniata, A. hispalensis, A. rectipennis y $A$. rufomarginalis. En esta ocasión, Escalera señaló la distribución geográfica de estas especies, que se reparten por la mitad meridional de la Península sin llegar a su extremidad más occidental. En una publicación posterior, Escalera incorporó al subgénero dos nuevas especies: A. inesperata y A. granosa (Escalera, 1921: 117).

Edmund Reitter en 1917 dividió la tribu Asidini para la región Paleártica en dos géneros: Alphasida Escalera, 1905 y Asida Latreille, 1802. El primero de estos es el más ampliamente representado por su alto número de especies. Él comprendía Alphasida s. st., Elongasida Escalera, 1906, Machlasida Escalera, 1907, Glabrasida Escalera, 1910 y otros nueve subgéneros nuevos, definidos en ese momento (Reitter, 1917: 8). Elongasida aparece ahí representado únicamente por Alphasida hesperica y, eventualmente, por A. hispalensis y A. rufomarginalis, que son citadas aunque el autor reconoce no haberlas podido examinar (op. cit.: 39); las especies A. grandipalpis y $A$. rectipennis son agrupadas en el nuevo subgénero Cribrasida (op. cit.: 38), y A. calumniata y A. alonensis, que Reitter admite igualmente no haber podido examinar, podrían ser consideradas según él como sinonimias respectivas de las precedentes de acuerdo con sus descripciones originales. La especie atípica A. asperata fue separada completamente del grupo e incorporada al subgénero Pedarasida (op. cit.: 29).
En nuestros días, Amador Viñolas y María del Carmen Cartagena en su revisión de los Tenebriónidos Ibero-Baleares (Viñolas \& Cartagena, 2008: 164) dieron a Elongasida un rango genérico, proponiendo una serie de cambios taxonómicos.

Soldati conservó Elongasida en la posición acordada por Reitter, pero atribuyéndole las diez especies señaladas por Escalera (Soldati, 2008: 128).

Por otro lado, describiendo especies nuevas de Marruecos, Escalera (1922: 173) creó el nuevo subgénero Pseudoelongasida, distribuido en la región noroccidental del país y formado por dos especies: Asida silvestrei (Escalera, 1922) y A. tenuecostata (Allard, 1869), esta última le era solo conocida a través de su descripción original.

En el volumen 5 del Catalogue of Palaearctic Coleoptera de Löbl \& Smetana el subgénero Pseudoelongasida aparece asimilado al género Asida y la especie Asida tenuecostata es designada incerta sedis (Soldati, 2008: 139). Más recientemente con el nuevo descubrimiento de la especie tipo en el MNHN, ésta ha sido reconocida bona species y el subgénero Pseudoelongasida ha sido transferido al género Alphasida (Pérez-Vera, 2012).

La nueva ordenación taxonómica de los subgéneros Elongasida y Pseudoelongasida ha conducido a la transferencia de Alphasida (Elongasida) asperata al subgénero Glabrasida. La similitud de esta especie con el grupo de Alphasida sicula (Solier, 1836) ha sido con frecuencia señalada (Allard, 1869: 286), así como la proximidad entre Alphasida sicula y Alphasida (Glabrasida) squalida (Allard, 1869) (Reitter, 1917: 30). Recientemente hemos designado Asida squalida nueva sinonimia de Asida asperata y transferido esta última especie al subgénero Glabrasida (Pérez-Vera \& Ávila, 2016: 122). Por un razonamiento análogo Alphasida (Elongasida) inesperata ha sido igualmente incorporada al grupo II de Glabrasida (Pérez-Vera \& Ávila, 2017: 370).

Finalmente, consideramos que la fusión de Pseudoelongasida y Elongasida en un solo grupo de dispersión hispano-marroquí esté bien justificada y esperamos que los próximos estudios moleculares puedan corroborar esta decisión.

\section{Material y métodos}

Hemos podido examinar el material tipo y a veces numerosas series de material no tipo que se conserva en el MNCN de Madrid, una buena parte del material 
procedente con frecuencia de capturas recientes de la Colección de Juan Carlos Martínez de Murcia, así como las colecciones del Departamento de Zoología de la Facultad de Ciencias de Granada. Igualmente, en una reciente visita, se ha podido examinar el material guardado en el MNHN de París.

Numerosos ejemplares han sido rehidratados siguiendo los procedimientos ya rutinarios (PérezVera \& Ávila, 2012a: 19) y algunos han sido disecados para el estudio de las genitalia macho y hembra. Hemos acumulado así una importante iconografía del material histórico y de ejemplares recientes. Siguiendo el procedimiento iniciado en nuestra revisión en curso del subgénero Glabrasida, hemos hecho aquí una descripción detallada de las genitalia, en particular de los ovipositores, acumulando un máximo de datos sobre la morfología de este órgano, con el objeto de seleccionar próximamente los elementos más discriminativos para el estudio taxonómico de la tribu Asidini (Pérez-Vera, 2014: 182). La utilización del léxico en latín pretende simplificar el tratamiento ulterior de los resultados acumulados.

\section{Abreviaturas utilizadas}

CA, colecciones de los autores, Universidad de Granada (Granada, España)

CJP, colección de M. Jesús Plaza (Madrid, España)

JCM, colección de Juan Carlos Martínez,

Universidad de Murcia (Murcia, España)

MNCN, Museo Nacional de Ciencias Naturales (Madrid, España)

MNHN, Muséum National d'Histoire Naturelle (París, Francia)

SG, colección de José Fermín Sánchez Gea, San Pedro del Pinatar (Murcia, España)

$\mathbf{L}$, longitud total del cuerpo

l, longitud del ovipositor

la, longitud de la pieza apical

lb, longitud de la pieza basal

$\mathbf{P a}$, longitud de los parámeros

$\mathbf{P h}$, longitud de la falobase

\section{Resultados}

Subénero Elongasida Escalera, 1906

Elongasida Escalera, 1906: 306. Especie tipo: Asida grandipalpis Allard, 1869

Cribrasida Reitter, 1917: 38. Especie tipo: Asida grandipalpis Allard, 1869

Pseudoelongasida Escalera, 1922: 173. Especie tipo: Pseudoelongasida silvestrei Escalera, 1922 syn. nov.

Caracteres diagnósticos.- Bien definido en su descripción original (Escalera, 1906: 306). Sus especies presentan un cuerpo alargado y más o menos paralelo, no estrechado o apenas a nivel de los húmeros, éstos más o menos redondeados pero jamás angulosos o divergentes; el protórax de bordes laterales ligeramente curvos, poco convergentes hacia delante y aún menos hacia atrás, cortantes y levantados, aunque menos que el disco, que es moderadamente convexo con el borde anterior escotado en arco de círculo, los ángulos anteriores agudos, el borde posterior con el lóbulo mediano iniciado lejos del canal marginal, poco saliente o truncado, los ángulos posteriores bien señalados, más o menos prolongados hacia atrás y jamás redondeados, el disco con un punteado denso, a veces confluente, provisto de una pubescencia dorada, corta y tendida hacia atrás, fácilmente caediza; la cara inferior del protórax reticulado-granulosa o granulosa; los élitros largos y poco convexos, de bordes muy poco ensanchados hacia atrás hasta el tercio posterior, donde después se estrechan rápidamente hacia el ápex, que es con frecuencia un poco acuminado; ellos están cubiertos por una granulación fina y densa, con pilosidad caediza, doradorojiza, más o menos larga; poseen dos costillas, en ocasiones lisas y patentes, reunidas de forma variable en sus extremidades posteriores; estas costillas emiten a veces pequeñas espículas laterales que pueden llegar a formar verdaderas anastomosis, circunstancia ésta más frecuente en las hembras. En ciertas ocasiones, las costillas están representadas por dos o tres series granulosas costiformes, más o menos interrumpidas, que tienden a hacerse más o menos obsoletas, sobre todo en los machos. Las patas son largas y fuertes, las protibias no denticuladas, solo con el diente apical bien desarrollado. Las antenas finas y más o menos largas, con todos los segmentos notablemente más largos que anchos, salvo el décimo que es transverso y el onceavo que es globular y no demasiado encastrado en el precedente.

La descripción del subgénero Pseudoelongasida (Escalera, op. cit.) es muy similar, con algunas diferencias en relación con las antenas y las patas, que son algo más cortas, y con la costulación elitral, que presenta una tercera costilla lateral constante. Estas diferencias son consideradas menores y ampliamente compensadas por la similitud de los dos grupos, que permite la inclusión del conjunto de especies en una Clave de Identificación común.

COMPOSICIÓN ESPECIFICA.- Con la transferencia de asperata y de inesperata al subgénero Glabrasida, el número de especies quedaría reducido a ocho, pero se han agregado dos especies nuevas, guardadas in schedula con el material del MNCN y las dos especies incorporadas tras la fusión de los dos subgéneros. En consecuencia, las doce especies nuevamente reconocidas serían las siguientes (en orden alfabético): Alphasida (Elongasida) alonensis (Martínez \& Sáez, 1873); Alphasida (Elongasida) calumniata (Escalera, 1906); Alphasida (Elongasida) grandipalpis (Allard, 1869); Alphasida (Elongasida) granosa (Escalera, 1921); Alphasida (Elongasida) hesperica (Rambur, 1838); Alphasida (Elongasida) hispalensis (Escalera, 1906); Alphasida (Elongasida) levantina sp. nov.; Alphasida (Elongasida) moroderi sp. nov.; 
Alphasida (Elongasida) rectipennis (Escalera, 1906); Alphasida (Elongasida) rufomarginalis (Escalera, 1906); Alphasida (Elongasida) silvestrei (Escalera, 1922) comb. nov.; Alphasida (Elongasida) tenuecostata (Fairmaire, 1880) comb. nov.

Distribución GEOGRÁFICA.- Los taxones específicos y subespecíficos del grupo se reparten en la zona centro-meridional de la Península Ibérica y en la región noroccidental de Marruecos (fig. 1)

\section{Clave de especies del subgénero Elongasida}

1 Costillas elitrales más o menos enteras, lisas y levantadas, avecesacompañadas de unao devariasseriesmuyinterrumpidas de granulaciones de tipo tuberculoide semejantes a costillas suplementarias.

.....2

- Costillas elitrales poco distinguibles, muy fraccionadas, con frecuencia reducidas a simples pliegues costiformes, también a veces acompañadas de granulaciones tuberculoides, variablemente ordenadas. Grupo grandipalpis..

6

2 Cada élitro con dos costillas dorsales, más o menos enteras, que se fusionan en la declividad posterior; frecuentes series suplementarias de granulaciones costiformes.

Grupo hesperica..................................................................3

- Cada élitro con tres costillas enteras bien levantadas y brillantes, las dos primeras reunidas en la declividad posterior y su prolongación más o menos fusionada con la tercera costilla cerca del ápex; los valles intercostales cubiertos por una granulación fina y uniforme. Grupo silvestrei.

5

3 Cuerpo estrechamente oval, sub-paralelo en el macho, bastante pubescente, la pilosidad dorada y larga bien manifiesta sobre el pronoto y sobre los élitros; la primera costilla dorsal, naciendo de la base, gruesa y fuerte en su primer tercio, después interrumpida y variablemente señalada hasta el ápex; la segunda costilla enteramente entrecortada y menos manifiesta. Osuna, Benacazón (Sevilla) Provincia de Badajoz.

Alphasida hispalensis (Escalera, 1906)

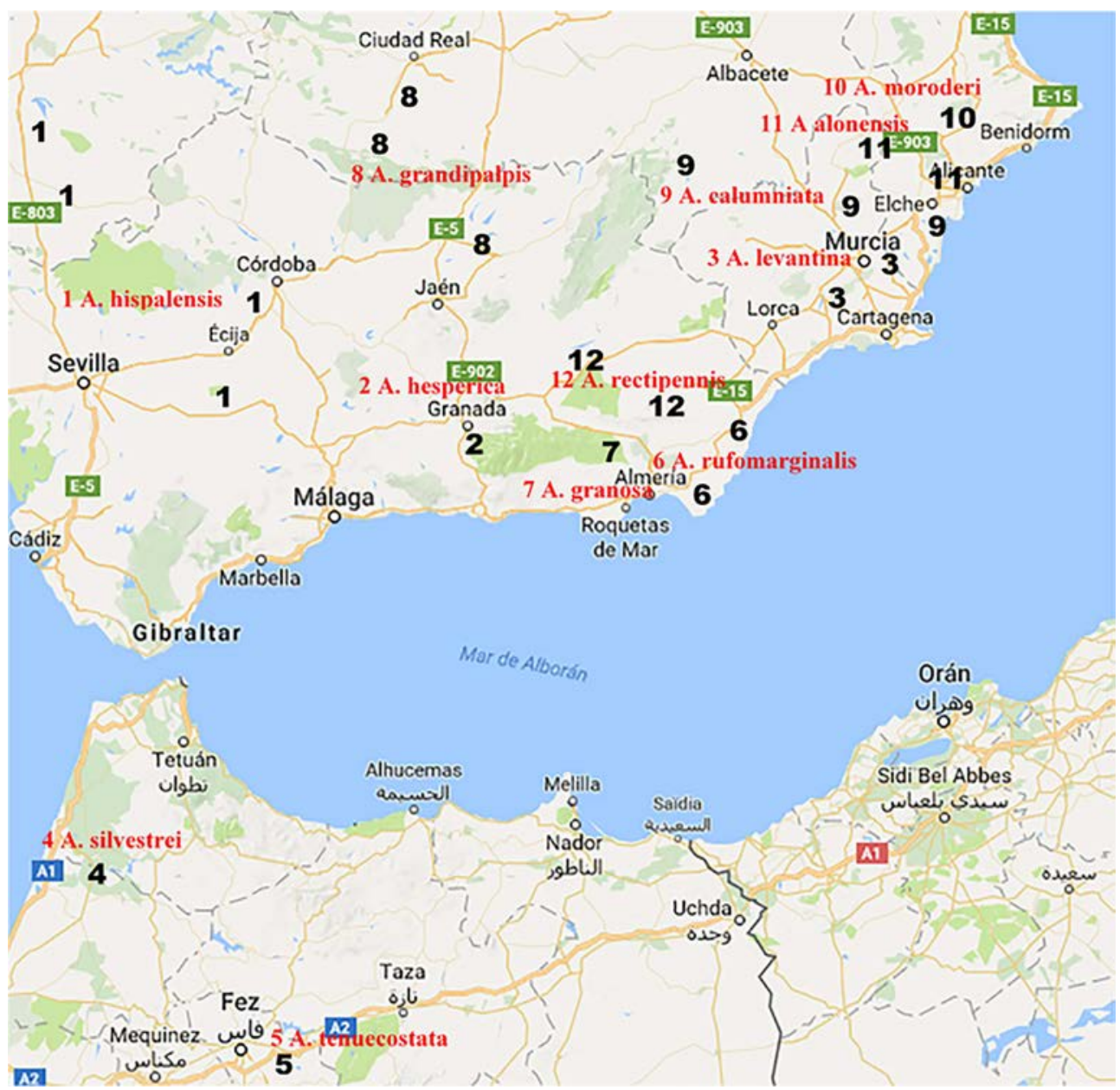

Fig. 1.- Distribución geográfica de las especies del subgénero Elongasida: 1, Alphasida hispalensis; 2, A. hesperica; 3, A. levantina; 4, A. silvestrei; 5, A. tenuecostata; 6, A. rufomarginalis; 7, A. granosa; 8, A. grandipalpis; 9, A. calumniata; 10 , A. moroderi; 11, A. alonensis; 12 , A. rectipennis.

Fig. 1.- Geographical distribution of the species of the subgenus Elongasida: 1, Alphasida hispalensis; 2, A. hesperica; 3 , A. levantina; 4, A. silvestrei; 5, A. tenuecostata; 6, A. rufomarginalis; 7, A. granosa; 8, A. grandipalpis; 9, A. calumniata; $10, A$. moroderi; $11, A$. alonensis; 12 , A. rectipennis. 
Cuerpo muy paralelo y alargado en el macho, estrechamente oval en la hembra, mucho menos pubescente que en la especie precedente; las dos costillas más enteras y levantadas...

4 Las dos costillas dorsales bastante bien señaladas; los intervalos con una granulación discretamente irregular pero siempre fina, las series de gruesas granulaciones tuberculoides bastante raras en el macho y discretamente manifiestas en la hembra. Granada

A. hesperica (Rambur, 1838)

Las dos costillas principales algo menos individualizadas, por el contrario, las series costiformes, en número de tres o cuatro, apareciendo muy manifiestas en los dos sexos. Totana, San José de la Vega, Alquerías, Librilla (Murcia).

A. levantina sp. nov.

5 Pronoto muy poco transversal de bordes redondeados en curva más pronunciada hacia delante y casi paralelos hacia atrás, las márgenes anchas y aplanadas sin canal marginal bien perceptible. Región atlántica de Ksar el Kbir (Marruecos).

A. silvestrei (Escalera, 1922)

Pronoto aún menos transverso, los bordes menos curvilineos, convergentes hacia delante y paralelos hacia atrás, las márgenes regularmente estrechas y levantadas con un canal marginal bien definido. Región interior de $\mathrm{Fez}$ (Marruecos)..

A. tenuecostata (Fairmaire, 1880)

6 Ángulos posteriores del pronoto agudos y más salientes hacia atrás que el lóbulo medio, recubriendo los húmeros.

7

Ángulos posteriores del pronoto rectos, poco salientes hacia atrás, menos prolongados o sobrepasando apenas el lóbulo medio y no recubriendo los húmeros... ...11

7 Cuerpo bastante paralelo con los élitros bruscamente estrechados por detrás pero no acuminados; márgenes del protóraxanchas ylevantadas...

- Cuerpo alargado, estrechamente oblongo con los élitros acuminados al ápex; márgenes del protórax más o menos anchas...

8 Márgenes del pronoto rojizas y translúcidas, con el borde exterior densamente ciliado, las sedas claras y tendidas hacia atrás; el punteado discal casi redondo, bien marcado, denso y confluente; los élitros sin costillas manifiestas, la primera dorsal apenas señalada por un pliegue muy poco levantado; las series de granulaciones tuberculoides más definidas en las hembras. Especie localizada en la región sur-oriental de la provincia de Almería.

A. rufomarginalis (Escalera, 1906) Márgenes del pronoto del mismo color que el disco; el punteado discal alargado y rasposo con los gránulos más gruesos en las declividades y sobre los ángulos posteriores y las márgenes; los élitros con tres pliegues costales, de los cuales solo el primero dorsal es costiforme y entero en su mitad anterior. Vertiente norte de la Sierra de Gádor (Almería)

A. granosa (Escalera, 1921)

9 Insectos de talla mediana (14 a $17 \mathrm{~mm}$ ); márgenes del protórax bien anchas y levantadas; en la cara ventral del margen, una larga zona lisa muy brillante a todo lo largo del canal marginal, desprovista de granulaciones o de pliegues; élitros sin costillas o estas vestigiales; la declividad apical apenas pronunciada, el ápex mismo acuminado pero no caudiforme; último segmento de los palpos maxilares bastante grande en los machos. Ciudad Real y norte de Jaén
Insectos de talla grande (16,5 a $19 \mathrm{~mm})$; márgenes del protórax en general menos anchas; en la cara ventral ausencia de zona lisa por debajo del canal marginal: élitros con o sin costillas y si están presentes poco levantadas; la declividad apical más o menos pronunciada y la extremidad netamente caudiforme; último segmento de los palpos maxilares en el macho grande o pequeño.

.10

10 Palpos maxilares grandes; élitros con menor declividad apical, sin pliegues costiformes aunque a veces se pueden apreciar trazos longitudinales formados por gránulos mayores, sobre todo en las hembras. Norte de la provincia de Murcia y sur de Albacete............................... calumniata (Escalera, 1906) Palpos maxilares más pequeños; élitros de fuerte declividad apical, con tres pliegues costiformes poco levantados pero bien definidos en los dos sexos, en las hembras con series secundarias de gránulos en número variable. La Encina (Alicante).

A. moroderi sp. nov.

11 Cuerpo negro, brillante, con granulación elitral fuerte y densa; pliegues costales bien definidos: élitros con la máxima anchura en el tercio posterior; declividad apical fuerte, muy brusca y ápex brevemente caudiforme. Alicante.......................A. alonensis (Martínez \& Sáez, 1873) Cuerpo negro o marrón oscuro, mate, con granulación elitral más fina y menos densa; pliegues costales poco definidos; élitros con la máxima anchura en el centro, la declividad apical poco pronunciada. Huercal Overa, Tijola (Almería), Galera (Granada).

A. rectipennis (Escalera, 1906)

\section{Catálogo comentado de las especies}

\section{Alphasida (Elongasida) alonensis (Martínez y Sáez,} 1873) (figs. 2-8)

Asida alonensis Martínez y Sáez, 1873: 409

Asida (Elongasida) alonensis Martínez y Sáez: Escalera, 1906: 310 Elongasida aleonensis aleonensis (Martínez y Sáez): Viñolas \& Cartagena, 2008: 168

Alphasida (Elongasida) alonensis (Martínez y Sáez): Soldati, 2008: 128

\section{Locus TYPICUS. - Alicante.}

Tipos examinados.- 10ิ (fig. 2), Asida alonensis Mart. Alicante (al verso: Rico! tipo de figura) [etiqueta blanca manuscrita]; 5 [pequeña etiqueta blanca manuscrita]; Holotipo [etiqueta roja impresa]; Alphasida (Elongasida) alonensis Martínez ô, A. Cobos det. 1985 [etiqueta blanca manuscrita]; MNCN Cat. Tipos $\mathrm{n}^{\circ} 12220$ [etiqueta roja impresa]; MNCN_Ent 107352 [etiqueta gris impresa] (MNCN). 1̄̄ (fig. 3), Alicante (verso Rico! tipo de figura) [etiqueta blanca manuscrita]; 4 [pequeña etiqueta blanca manuscrita]; Allotipo [etiqueta roja impresa]; Alphasida (Elongasida) alonensis Martínez + , A. Cobos det. 1985 [etiqueta blanca manuscrita]: MNCN Cat. Tipos $\mathrm{n}^{\circ} 12220$ [etiqueta roja impresa]; MNCN_Ent 107353 [etiqueta gris impresa] (MNCN).

Otro material examinado. -1 q, Villena (A) IV-2012, David M. leg, ex Coll. JCM (CA). 
Dimensiones.- La talla del macho holotipo es de 16,5 $\mathrm{mm}$, las dos hembras examinadas miden $18 \mathrm{~mm}$ de largo.

COMPLEMENTOS DE DESCRIPCIÓN.- El edeago presenta una falobase sensiblemente más larga, más robusta y más convexa ventralmente que los parámeros (fig. 4), el índice $\mathrm{Ph} / \mathrm{Pa}=1,18$; los parámeros de una silueta bastante particular en visión dorsal: los bordes rectos y paralelos en sus $3 / 5$ basales, después muy brevemente incurvados y luego rectos y paralelos hasta el ápex, que es romo y cortamente hendido en el medio; el endofalo es un poco aplanado por encima de su base y después robusto y regular hasta su extremidad redondeada.

EL ovipositor (fig. 5) largo y fuerte, el índice $\mathrm{L} / 1=1,96$, el índice $\mathrm{lb} / \mathrm{la}=4,71$; la sinuosidad dorsal de los paraprocta muy pronunciada, en la mitad basal del tronco, la extremidad distal truncada recta con el ángulo dorsal muy redondeado; los epicolpos muy robustos, con la extremidad distal en curva asimétrica

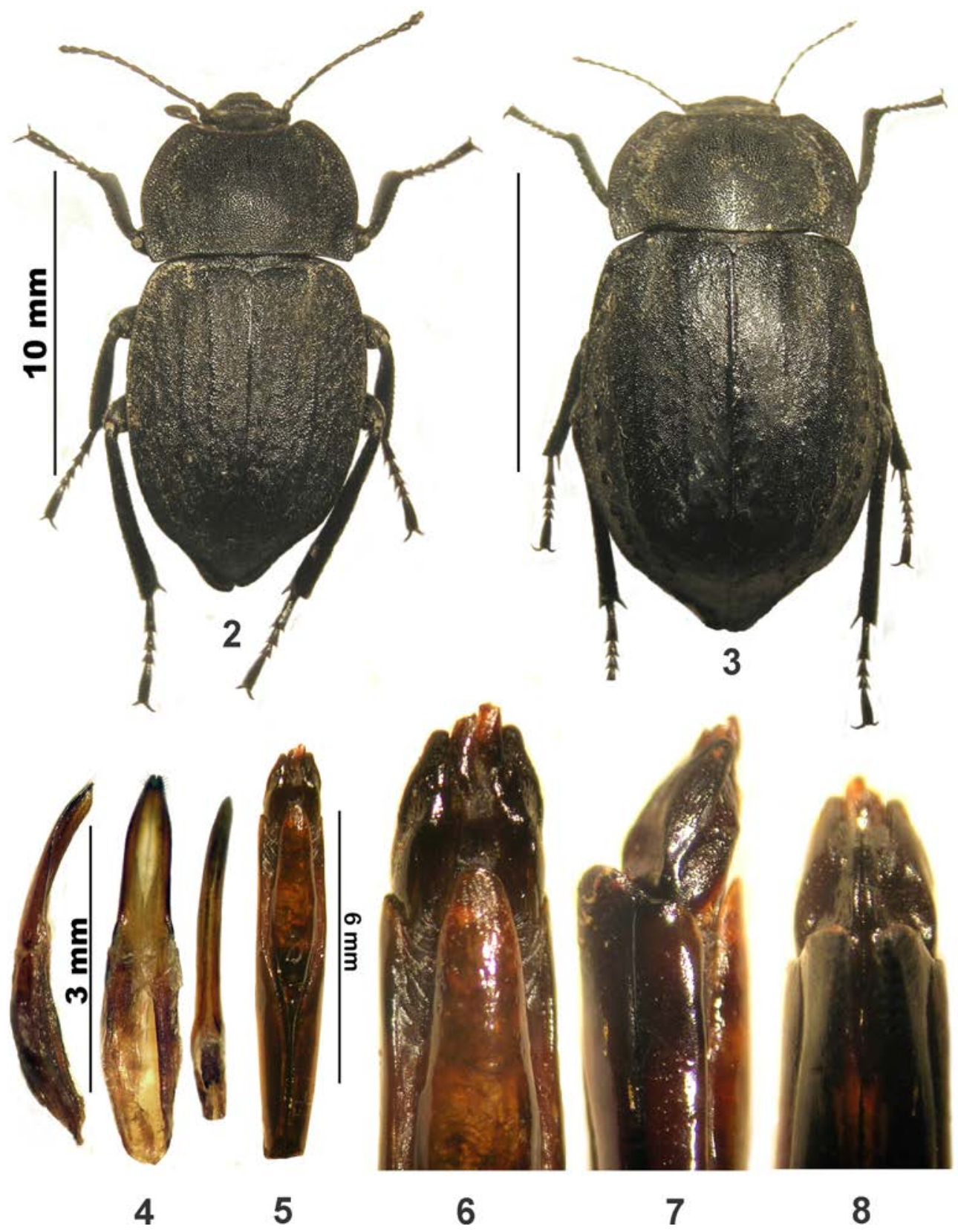

Figs. 2-8.- Alphasida (Elongasida) alonensis (Martínez y Sáez, 1873): 2, habitus del Holotipo đ̂̉ MNCN 107352; 3, habitus del Paratipo 9 MNCN 107353; 4, vista lateral del edeago y vista dorsal de la pieza principal y del endofalo: 5. ovipositor, vista dorsal; $6-8$, extremidad del mismo en vistas dorsal, lateral y ventral.

Figs. 2-8.- Alphasida (Elongasida) alonensis (Martínez y Sáez, 1873): 2, habitus of the Holotypus MNCN 107352; 3, habitus of the 9 Paratypus MNCN 107353; 4, side view of aedeagus and dorsal view of principal piece and endophallus; 5 , ovipositor, dorsal view; $6-8$, dorsal, lateral and ventral views of ovipositor top. 
con la superficie deslustrada por un punteado foveolado poco marcado pero denso. La pieza apical (figs. 6-8) está bastante desgastada en el ejemplar tipo aunque permite bien apreciar los principales detalles; el ovopositor del otro ejemplar $q$ examinado muestra las extremidades afiladas, cortas y no divergentes. La silueta es bi-sinuosa; la fossa analis oval con el fondo cortamente hendido en la extremidad. Los coxita dorsolateralia presentan la pars basalis con la cara dorsal brillante y un punteado fino y disperso, la cara lateral con punteado foveolado-granuloso, pilífero, bastante denso; la pars intermediana con el punteado aún más denso, las fosillas más definidas y la pilosidad más persistente; las partes distales lisas, cubren los sclerites vulvaris y se presentan menos desgastadas que las propias piezas excavadoras. Las coxita apicalia ofrecen un area dorsiapicalis con fina rugosidad mate, la pars lateralis con un punteado foveolado disperso, ordenado en estrías longitudinales, la cara ventral con puntos de trichobothria en el area intercoxitalis y el area basalis dejando una zona levantada y lisa a lo largo de la carena mediana. El scleritus vulvaris medianus normalmente esclerotizado.

Comentarios.- La especie está bastante bien definida por su morfología general, ampliamente detallada en su descripción original (Martínez y Sáez, 1873: 409), sus tegumentos negros y brillantes y los pliegues costales bien definidos son caracteres suficientemente discriminatorios, Así mismo las genitalia macho y hembra difieren de los de las especies más próximas Alphasida rectipennis y $A$. granosa que habían sido tratadas recientemente como subespecies de alonensis (Viñolas y Cartagena, 2005: 169)

DistRIBUCIÓN GEOGRÁFICA.- Señalada del centro-norte de la provincia de Alicante, colectas más recientes la sitúan igualmente en la región sur-oeste próxima de la provincia de Murcia.

Alphasida (Elongasida) calumniata (Escalera, 1906) (figs. 9-15)

Asida (Elongasida) calumniata Escalera, 1906: 311

Elongasida grandipalpis calumniata (Escalera): Viñolas \& Cartagena, 2008: 168

Alphasida (Elongasida) calumniata (Escalera): Soldati, 2008: 128

Locus TYPICUS.- Cobatillas, Murcia, Elche de la Sierra (Albacete), Torrevieja (Alicante) según la descripción original (Escalera, 1906) y de acuerdo con el artículo 73.2.3 (ICZN, 1999); tras la designación siguiente de Lectotipo, la localidad tipo es únicamente «Elche de la Sierra (Albacete)», de acuerdo con el artículo 76.2 del Código (ICZN, 1999).

TiPos eXAMinAdos.- LeCtotypus (presente designación): $\widehat{\jmath}$, Elche de la Sierra [Albacete] [etiqueta blanca impresa]; Sintipo [etiqueta roja impresa]; MNCN Cat. Tipos $\mathrm{n}^{\circ} 2514$ [etiqueta roja impresa]; Lectotypus de
Asida (Elongasida) calumniata Escalera, Pérez-Vera \& Ávila des. 2015 [etiqueta roja impresa]; MNCN Ent. 107333 [etiqueta gris impresa] (MNCN). Paralectotypus: 5 तe $3 q$ (Todos Covatillas, 19 Elche de la Sierra), ídem lectotype (MNCN).

Otro material examinado.- $1 \hat{\jmath}$, (Hellín, Albacete) $(\mathrm{MNCN}) ; 3 \hat{\jmath}$ et 2 오 (1へ Elche de la Sierra, el resto Jumilla (Murcia), J.L. Lencina leg) in coll. Cobos (MNCN); $1 \delta^{\Uparrow}$ y 1 \% , Murcia a Jumilla, 26.III.2011. J. Fermín leg. (CA).

DiMENSIONES.- Lectotipo $17 \mathrm{~mm}$ de largo; $\widehat{\partial} \widehat{\partial}$ de 15,5 a $17 \mathrm{~mm}$; 우우 de 17 a $19 \mathrm{~mm}$ de largo.

Complementos De DESCRIPCIÓN.- El macho (fig. 9) es muy similar al de Alphasida grandipalpis, con el último segmento de los palpos maxilares bastante grande, pero en él, la cara inferior del protórax es mate y está cubierta de pequeñas granulaciones en la parte lateral correspondiente al canal marginal; la parte posterior de los élitros presenta una declividad bien pronunciada pero no brusca y el ápex es moderadamente caudiforme.

El edeago (fig. 11), poco convexo ventralmente, presenta los parámeros muy ligeramente más largos que la falobase, con el índice $\mathrm{Ph} / \mathrm{Pa}=0,95$; la silueta parameral es ojival con los rebordes dorsales desapareciendo totalmente antes del ápex, que es muy aplanado; el endofalo, un poco aplanado pero no ensanchado a la base es robusto y regulas y muy brevemente aguzado al ápex.

La hembra (fig. 10) de palpos maxilares normales, presenta los élitros sin verdaderas costillas pero los gránulos gruesos y lisos del tegumento elitral están reunidos en trazos longitudinales de aspecto costiforme

El ovipositor (fig. 12) es largo y robusto, con índice $\mathrm{L} / \mathrm{l}=1,79$ e índice $\mathrm{lb} / \mathrm{la}=4,44$; la sinuosidad dorsal de los paraprocta muy pronunciada se encuentra en la mitad basal del tronco y su extremidad distal es claramente truncada recta; los epicolpos de extremidades distales muy oblicuas y redondeadas, el ángulo interno muy avanzado en sentido distal (fig. 15), la superficie es lisa y brillante. La pieza apical (figs. 13-15) de silueta bi-sinuosa con las extremidades divergentes; la fossa analis alargada y estrecha con el fondo brevemente hendido en su extremidad; los coxita dorsolateralia presentan la pars basalis con la cara dorsal ancha lisa y brillante y la cara lateral muy rugosa con una granulación irregular, pilífera; la pars intermediana con la granulación más densa y la pilosidad más persistente, las partes distales lisas. Los coxita apicalis presentan el area dorsoapicalis con una ligera rugosidad brillante, la pars lateralis estriada longitudinalmente con algunos puntos pilíferos dispersos, la fossula gonostyloidis con 2 o 3 setae apicalis; la cara ventral es bastante lisa con algunos trichobothria caducos a lo largo del area 

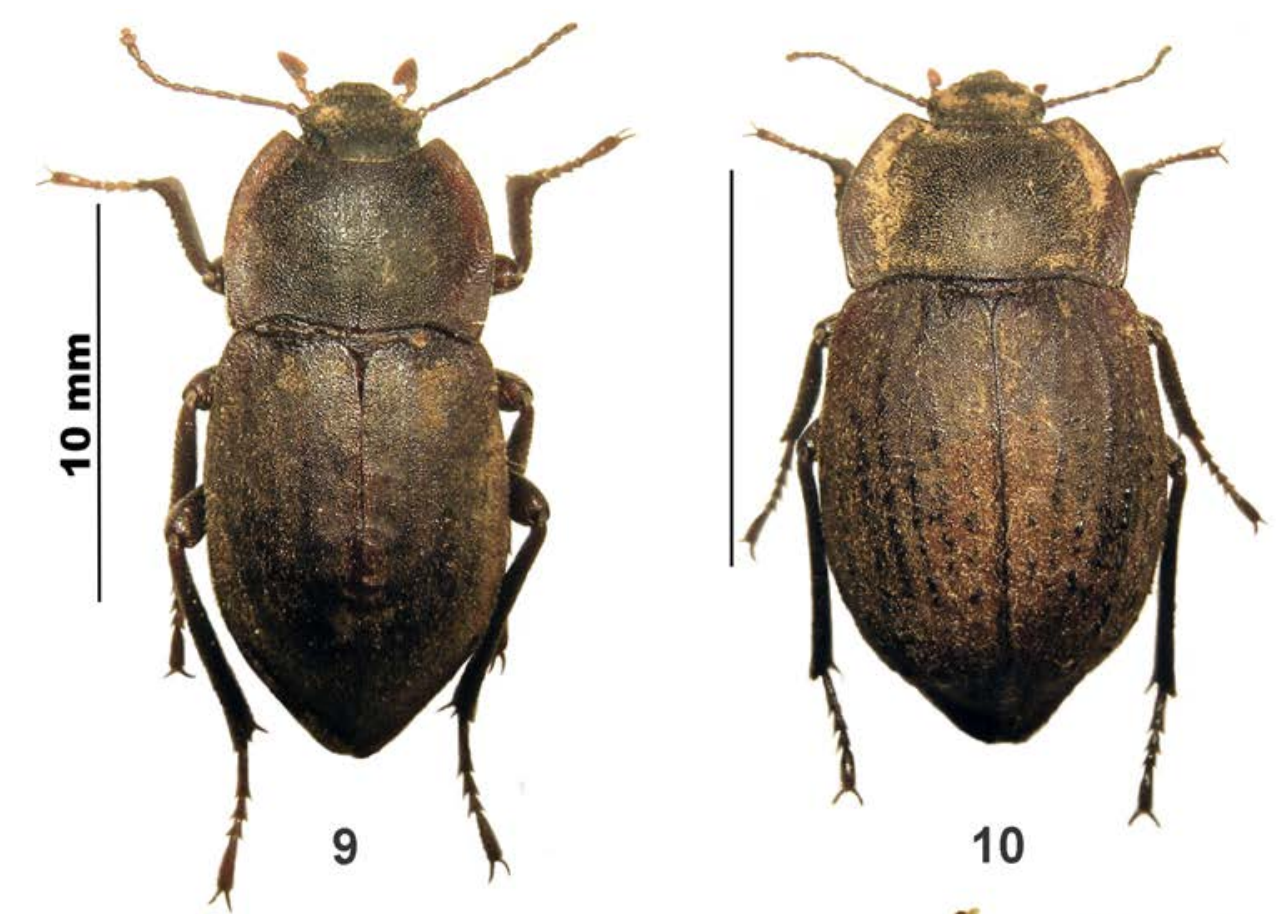

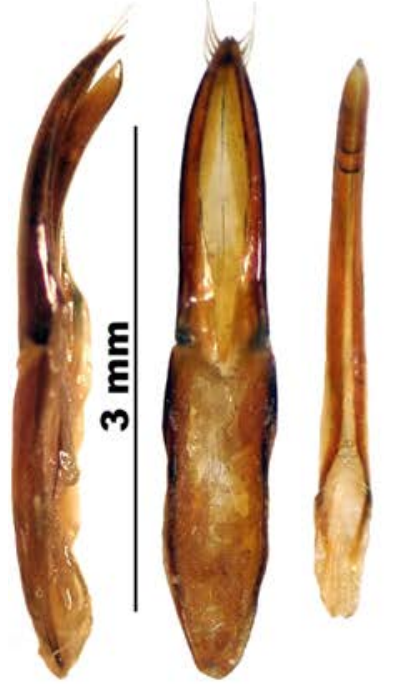

11

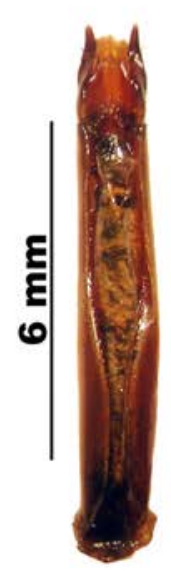

12

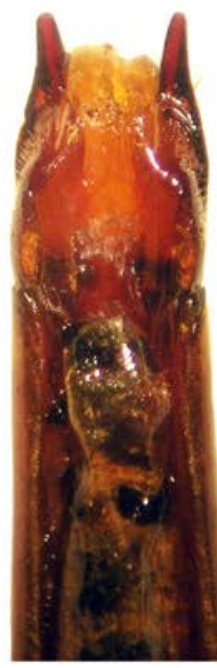

13

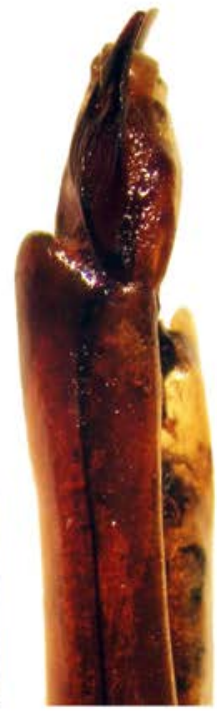

14

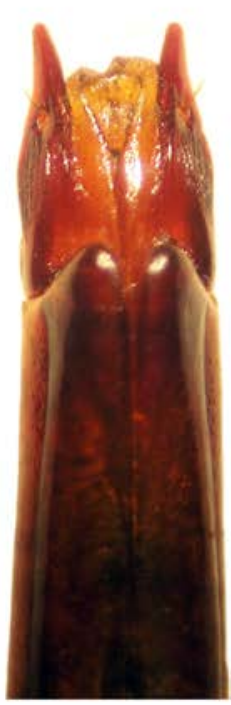

15

Figs. 9-15.- Alphasida (Elongasida) calumniata (Escalera, 1906): 9. Habitus del Lectotipo $ð$ MNCN 107333; 10, habitus del Paralectotipo $q$ MNCN 107338; 11, vista lateral del edeago y vista dorsal de la pieza principal y del endofalo: 12, ovipositor, vista dorsal; 13-15, extremidad del mismo en vistas dorsal, lateral y ventral.

Figs. 9-15.- Alphasida (Elongasida) calumniata (Escalera, 1906): 9, habitus of the ${ }^{7}$ Lectotypus MNCN 107333; 10, habitus of the $P$ Paralectotypus MNCN 107338; 11, side view of aedeagus and dorsal view of principal piece and endophallus; 12 , ovipositor, dorsal view; 13-15, dorsal, lateral and ventral views of ovipositor top.

ventriapicalis, las areae basales muy alargadas y lisas y el area intercoxitalis sin relieve longitudinal a cada lado de la carena mediana. El scleritus vulvaris medianus es bastante ancho y normalmente esclerotizado.

Comentarios.- Esta especie de palpos maxilares bastante grandes en los machos se diferencia esencialmente de la especie $A$. grandipalpis por su talla superior, las márgenes pronotales netamente menos anchas y los élitros con una declividad posterior bien acusada y la extremidad claramente caudiforme.

DistRIBUCIÓN GEOGRÁFICA.- La especie ocupa una zona bien definida que comprende el norte de la provincia de Murcia, el sur-este de la de Albacete y la región vecina de la provincia de Alicante. 
Alphasida (Elongasida) grandipalpis (Allard, 1869) (figs. 16-22)

Asida grandipalpis Allard, 1869: 288

Asida (Elongasida) grandipalpis Allard: Escalera, 1906: 310

Elongasida grandipalpis grandipalpis (Allard): Viñolas \&

Cartagena, 2008:167

Alphasida (Elongasida) grandipalpis (Allard): Soldati, 2008: 128.

LOCUS TYPICUS.- España.

Material eXaminado.- $1 \hat{0}$ y $1 \%$, Santa Elena, Vadollano (Jaén); $1 \delta^{\lambda}$ y 2 , Pozuelo de Calatrava;

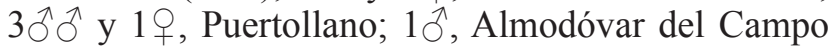

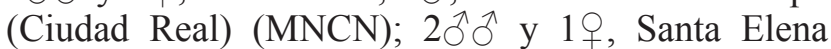
(Jaén) in coll. Cobos (MNCN); 1ठ̄, Pozuelo de Calatrava (Ciudad Real) (CA).

Dimensiones.- Especie de talla mediana, $\widehat{\partial} \widehat{\partial}$ de 14 a $15 \mathrm{~mm}$; 우 앙 16 a $17 \mathrm{~mm}$ de largo.

COMPLeMentos DE DESCRIPCIÓN.- El macho (fig. 16), presenta el último segmento de los palpos maxilares sécuriforme y bastante grande. La cara ventral del protórax con una banda longitudinal, correspondiendo dorsalmente al canal marginal, lisa y brillante, sin gránulos ni punteado. Les élitros, sin costillas o éstas muy vestigiales, muy aplanados, con los bordes gradualmente ensanchados hasta la mitad, después bruscamente estrechados hasta el ápex, tomando un aspecto acuminado pero no caudiforme; la declividad posterior apenas perceptible.

El edeago (fig. 18) es regularmente convexo en su cara ventral con la extremidad basal brevemente incurvadas, los parámeros casi tan largos como la falobase, el índice $\mathrm{Ph} / \mathrm{Pa}=1.11$; la silueta parameral es ojival y el endofalo, un poco aplanado a la base se estrecha transversalmente de forma progresiva hasta el ápex, que es sub-agudo.

La hembra (fig. 17), más convexa y más ancha que el macho, tiene los palpos normales. Los élitros con las costillas también muy vestigiales, pero los gránulos de los espacios intercostales son más marcados y más densos y forman 4 o 5 líneas longitudinales de aspecto costiforme.

El ovipositor (fig. 19) es en conjunto largo y esbelto, el índice $\mathrm{L} / \mathrm{l}=2$ y el índice $\mathrm{lb} / \mathrm{la}=3,33$; la sinuosidad dorsal de los paraprocta se sitúa en la mitad del tronco; la extremidad distal es muy oblicua; la de los epicolpos lo es mucho menos (fig. 22) y la superficie de estos es lisa y brillante. La pieza apical (fig. 20-22) es bastante alargada, de silueta ligeramente sinuosa con las extremidades un poco divergentes; la fossa analis alargada y estrecha. Los coxita dorsolateralia, presentan la pars basalis con la cara dorsal lisa y brillante y la cara lateral con un punteado irregular poco denso, pilífero; la pars intermediana con una fina granulación más densa y pilosidad persistente; la pars distalis lisa. Los coxita apicalia claramente recurvados en la extremidad en sentido dorsal, con el area dorsiapicalis acanalada y cubierta de una ligera rugosidad brillante; la pars lateralis estriada longitudinalmente con algunos puntos pilíferos dispersos, la fossula gonostyloidis bien marcada con 2-3 largas setae apicalis. La cara ventral con tres filas de puntos portadores de trichobothria en el area intercoxitalis, las areae basales alargadas y lisas. El scleritus vulvaris medianus normalmente esclerotizado.

Comentarios.- No conseguimos localizar el material tipo de esta especie en las colecciones del MNHN. En la descripción original (Allard, 1869: 288) se señalan como elementos discriminatorios de la especie, las márgenes pronotales anchas y poco levantadas, la forma general alargada, subparalela, no estrechada en los húmeros, y los élitros fuertemente deprimidos en su cara dorsal, bruscamente estrechados en su cuarto posterior y acuminados al ápex, con dos pliegues longitudinales muy poco marcados. Escalera insiste sobre la ausencia de costillas o su carácter vestigial y anota como detalle particular (Escalera, 1906: 311) la presencia de una banda lisa y brillante, desprovista de reticulaciones o de gránulos en la cara inferior del protórax a lo largo de la cara ventral del canal marginal.

DistRIBUCIÓN GEOGRÁFICA. - La especie se localiza en la provincia de Ciudad Real y en el Norte de la provincia de Jaén.

Alphasida (Elongasida) granosa (Escalera, 1921) (figs. 23-29)

Asida (Elongasida) granosa Escalera, 1921: 117

Elongasida aleonensis granosa Escalera: Viñolas \& Cartagena, 2008: 169

Alphasida (Elongasida) granosa (Escalera): Soldati, 2008: 128

Locus TYPICUS. - Bentarique (Almería).

TIPO EXAMINADO. $-1 \%$ : Bentarique [etiqueta blanca impresa]; Holotipo [etiqueta roja impresa]; MNCN Cat. Tipos no 12233 [etiqueta roja impresa]; Alphasida (Elongasida) rufomarginalis ssp granosa Esc. A. Cobos det [etiqueta blanca manuscrita]; $\mathrm{MNCN}_{-}$ Ent. $\mathrm{N}^{\circ}$ Cat. 71405 [etiqueta gris impresa] (MNCN). Designada Holotipo por monotipia.

Otro material eXAMinado.- $1 \delta^{\Uparrow}$ y 1 , Almería, Huéneja-Alicun (Almería) Hispania A. Cobos; 28 ejemplares (14 ${ }^{\lambda}{ }^{\lambda}$ y 14 웅), Terque (Almería) XI-59, A. Cobos leg, Alphasida (Elongasida) rufomarginalis ssp granosa Esc. A. Cobos det, 'comparada con el tipo', en Colección A. Cobos (MNCN); 10 y y 1 , Terque (Almería) XI-59 A. Cobos leg. (CA).

DiMENSIONES. - + holotipo $18 \mathrm{~mm}$; $\widehat{\jmath} \widehat{\partial}$ de 14 a 15,5 $\mathrm{mm}$; 우 de 17 a $19 \mathrm{~mm}$ de largo.

COMPLeMentos DE DESCRIPCIÓN.- El macho (fig. 23) presenta un protórax con el disco poco convexo, las 

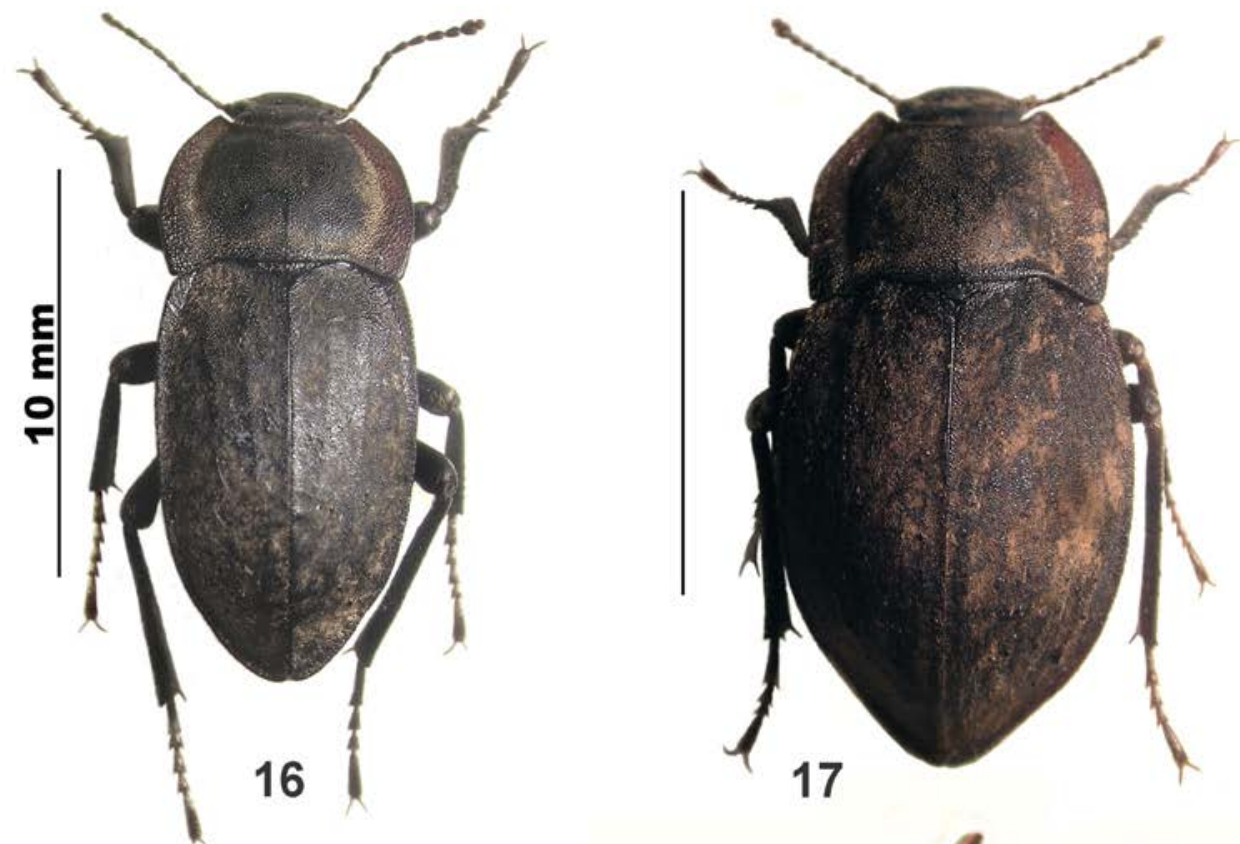

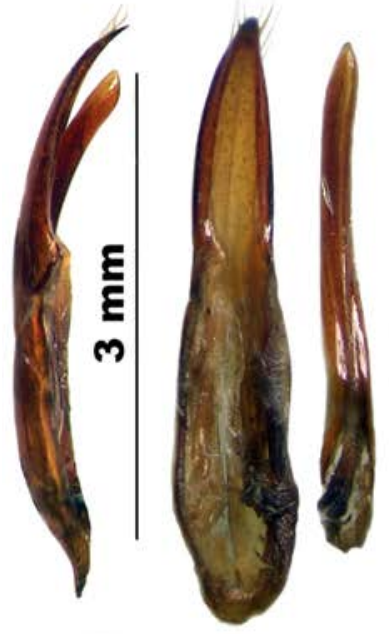

18

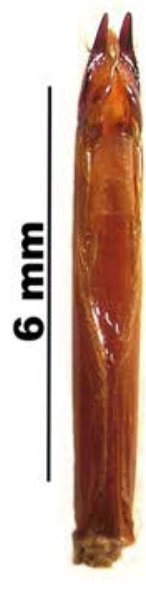

19

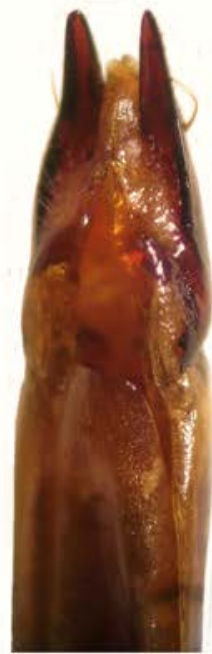

20

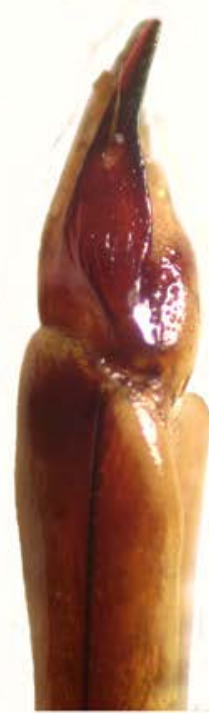

21

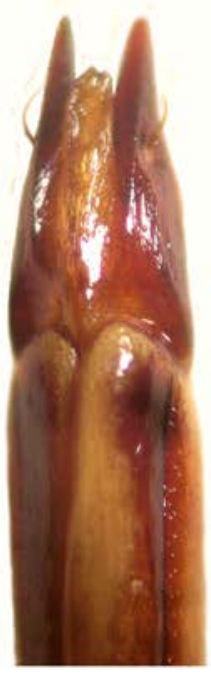

22

Figs. 16-22.- Alphasida (Elongasida) grandipalpis (Allard, 1869): 16, Habitus del ${ }^{1}$ MNCN 107342; 17, habitus de la ㅇ MNCN 107346; 18, vista lateral del edeago y vista dorsal de la pieza principal y del endofalo: 19, ovipositor, vista dorsal; 20-22, extremidad del mismo en vistas dorsal, lateral y ventral.

Figs. 16-22.- Alphasida (Elongasida) grandipalpis (Allard, 1869): 16, habitus of the MNCN 107342; 17, habitus of the 9 MNCN 107346; 18, side view of aedeagus and dorsal view of principal piece and endophallus; 19, ovipositor, dorsal view; 20-22, dorsal, lateral and ventral views of ovipositor top.

márgenes anchas y bien levantadas, finas, el lóbulo mediano bien acusado pero menos saliente que los ángulos posteriores; el punteado oblongo y un poco rasposo con pequeñas elevaciones que hacia las márgenes y sobre los ángulos posteriores se transforman en auténticos gránulos; los élitros cubiertos de una granulación muy fina, con tres costillas de las cuales solo la mitad anterior de la primera dorsal es entera, las restantes, menos señaladas, formadas por series longitudinales de gránulos más fuertes que los del fondo; entre las costillas se pueden ver series de granulaciones más fuertes, que en la parte posterior pueden estar más señaladas que las propias costillas.

El edeago (fig. 25) presenta los parámeros un poco más cortos que la falobase, el índice $\mathrm{Ph} / \mathrm{Pa}=1,12$; la silueta parameral ojival, estrechada al nivel de los tubérculos dorsales; el endofalo, aplastado a la base y en su mitad basal, se estrecha en la mitad distal hasta un ápex sub-agudo.

La hembra holotipo (fig. 24) es de talla superior a la de los machos pero sus características son similares. Debió ser disecada con anterioridad porque su ovipositor ha 

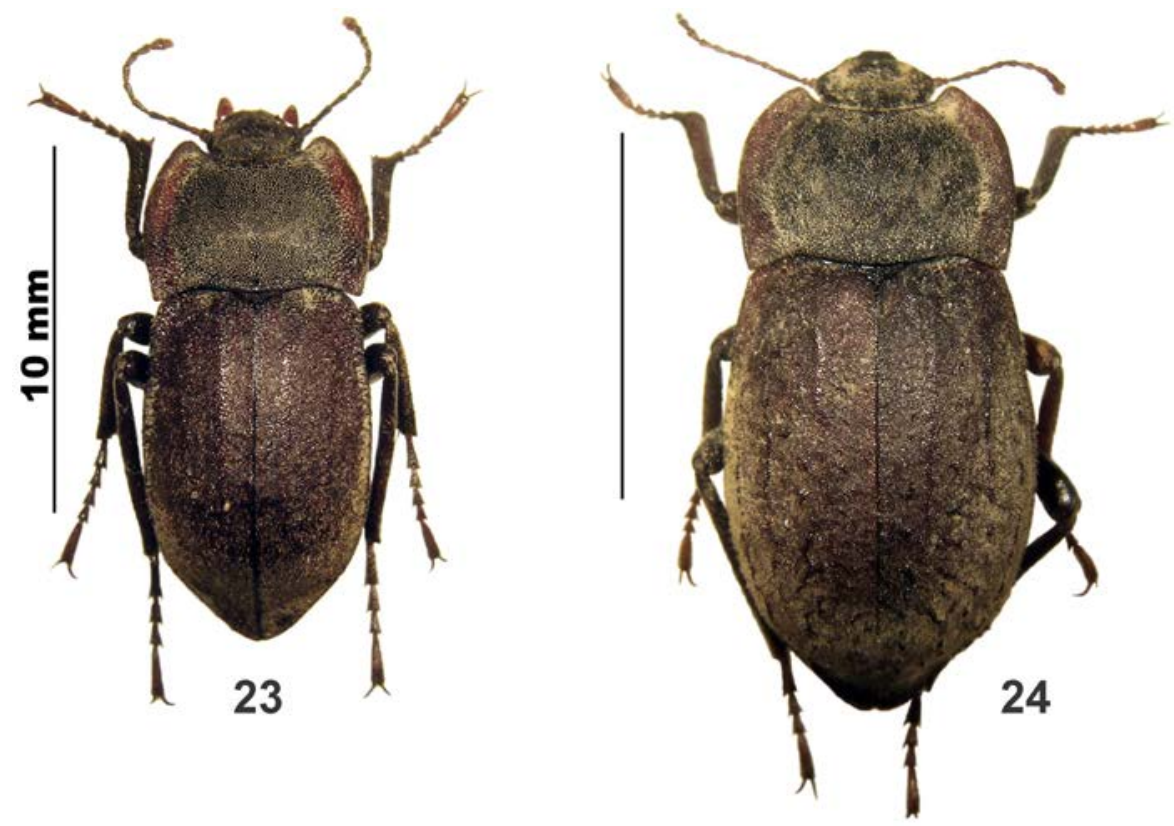

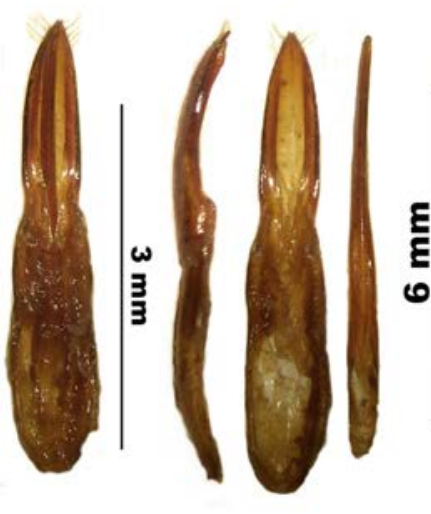

25

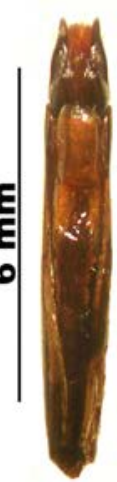

26

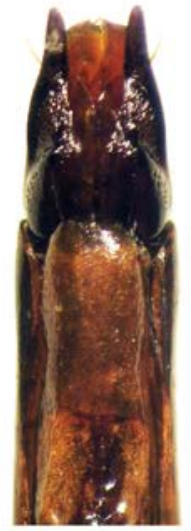

27

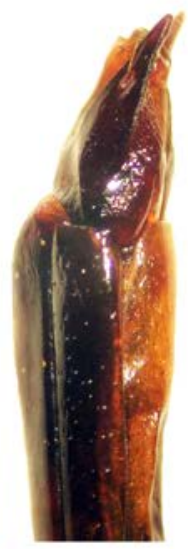

28

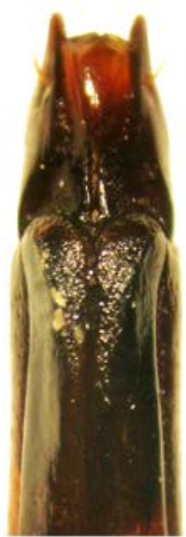

29

Figs. 23-29.- Alphasida (Elongasida) granosa (Escalera, 1921): 23, habitus del đ̊ MNCN 195047; 24, habitus del Holotipo $ᄋ$ MNCN 71405; 25, vistas dorsal y lateral del edeago y vista dorsal de la pieza principal y del endofalo: 26, ovipositor, vista dorsal; 27-29, extremidad del mismo en vistas dorsal, lateral y ventral.

Figs. 23-29.- Alphasida (Elongasida) granosa (Escalera, 1921): 23, habitus of the $\sigma^{1}$ MNCN 195047; 24, habitus of the + Holotypus MNCN 71405; 25, dorsal and side view of aedeagus and dorsal view of principal piece and endophallus; 26 , ovipositor, dorsal view; $27-29$, dorsal, lateral and ventral views of ovipositor top.

sido retirado y perdido $(\mathrm{i})$, aunque su spiculum ventral ha sido encontrado y montado con el spécimen.

El ovipositor (fig. 26) bastante robusto, con índice $\mathrm{L} / 1=2.16$ e índice $\mathrm{lb} / \mathrm{la}=4.39$ : la sinuosidad del borde dorsal de los paraprocta casi a la base del tronco; la extremidad distal prácticamente truncada recta con los ángulos vivos; la de los epicolpos regularmente redondeada y divergente (fig. 29), con la superficie finamente rugosa y deslustrada. La pieza apical (figs. 27-29) de silueta bi-sinuosa con las extremidades un poco divergentes; la fossa analis alargada y bastante estrecha, hendida en el centro en su porción apical. Los coxita dorsolateralia con la pars basalis de cara dorsal muy ancha, lisa, brillante y apenas sin punteado, la cara lateral con punteado irregular poco denso, pilífero, sobre un fondo rugoso; la pars intermediana con una fina granulación densa, de pilosidad persistente sobre un fondo estriado longitudinalmente; la pars distalis corta y lisa; los sclerites vulvaris laterales grandes, bien individualizados y esclerotizados. Los coxita apicalia presentan el area dorsiapicalis con una ligera rugosidad brillante, la pars lateralis bastante lisa con algunos puntos pilíferos dispersos, la fossula gonostyloidis bien marcada con 1-2 cortas setae apicalis; la cara ventral con raros puntos portadores de trichobothria sobre las estrechas areae intercoxitales, la carena mediana con un reborde glabro en su parte basal; las areae basales finamente estriadas longitudinalmente. El scleritus vulvaris medianus normalmente esclerotizado. 
Comentario.- Contrariamente a la idea de Viñolas de hacer de esta especie una subespecie de alonensis (Viñolas \& Cartagena, 2005: 169) nosotros encontramos que no hay razones ni a nivel de la morfología general ni aún menos a nivel de las genitalia que justifiquen la pérdida de su rango específico.

DiSTRIBUCIÓN GEOGRÁFICA.- $\mathrm{Su}$ localización muy circunscrita en el valle del río Andarax y la vertiente norte de la Sierra de Gádor (Almería) justificaría la protección de la especie.

Alphasida (Elongasida) hesperica (Rambur, 1838) (figs. 30-36)

Asida hesperica Rambur, 1838: P1. XX, 1-2.

Asida (Elongasida) hesperica Rambur: Escalera, 1906: 309

Elongasida hesperica hesperica (Rambur): Viñolas y Cartagena, 2008: 166
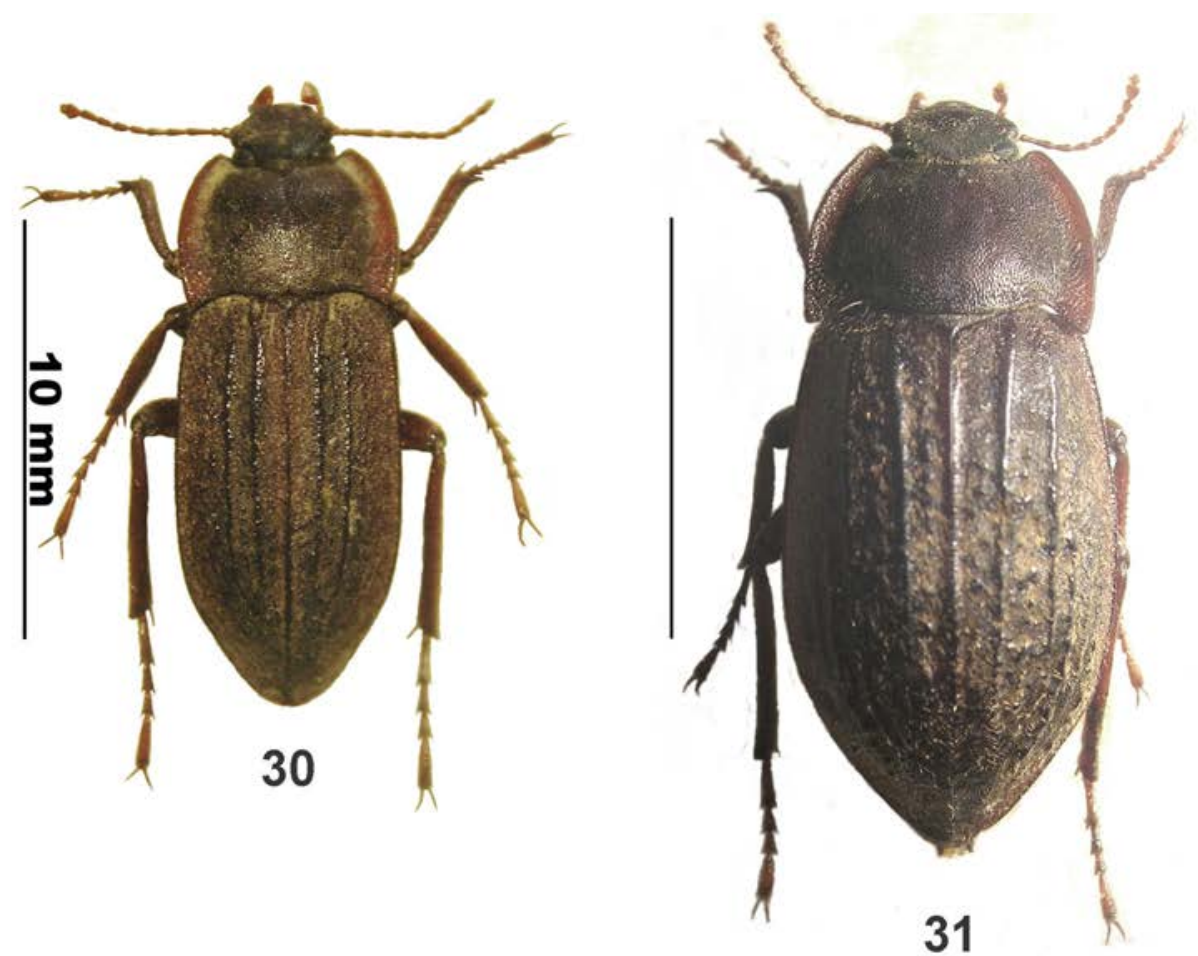

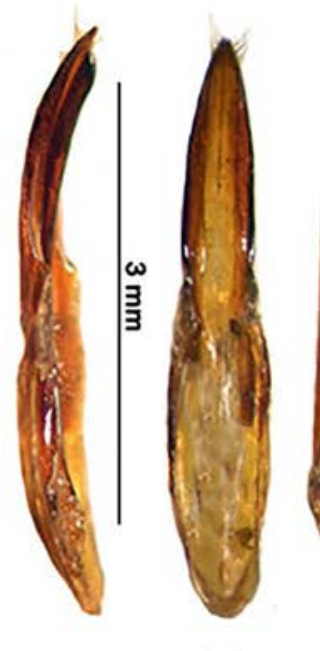

32

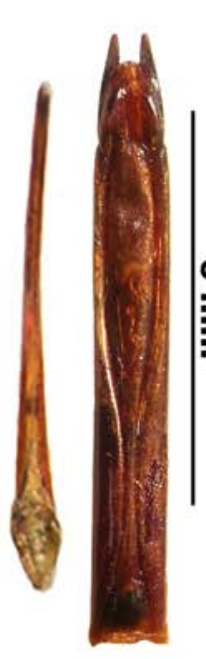

33

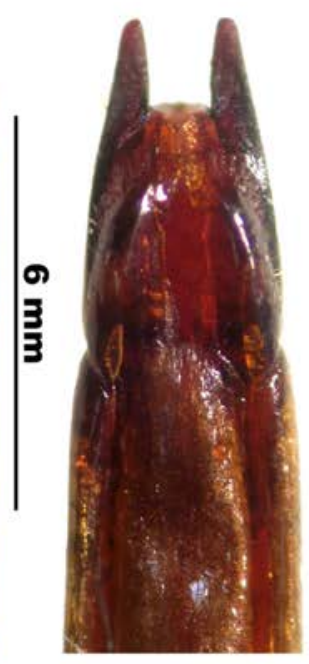

34

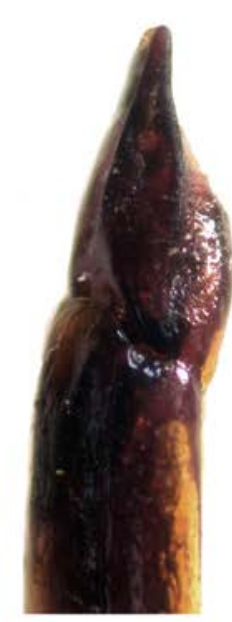

35

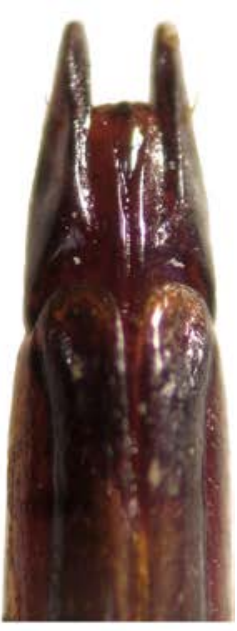

36

Figs. 30-36.- Alphasida (Elongasida) hesperica (Rambur, 1838): 30, habitus del $\widehat{\partial}$ (CA); 31, habitus de la $\bigcirc$ (CA); 32, vistas dorsal y lateral del edeago y vista dorsal de la pieza principal y del endofalo: 33, ovipositor, vista dorsal; 34-36, extremidad del mismo en vistas dorsal, lateral y ventral.

Figs. 30-36.- Alphasida (Elongasida) hesperica (Rambur, 1838): 30, habitus of the (CA); 31, habitus of the + (CA); 32, dorsal and side view of aedeagus and dorsal view of principal piece and endophallus; 33, ovipositor, dorsal view; 34-36, dorsal, lateral and ventral views of ovipositor top. 
Alphasida (Elongasida) hesperica (Rambur): Soldati, 2008: 128

Locus TYPICUS. - Sin localidad.

MATERIAL EXAMINADO.- 112 ejemplares: $8 \widehat{0} \widehat{o}$ y 4 우 Cenes Vega; 19 Churriana de la Vega; 19 La Zubia; 10 y 3 q 9 Loja (Granada); 22 ejemplares de ambos sexos Andalucía; 21 ejemplares de ambos sexos

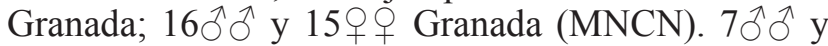
13 우 Cenes, Monachil, Dilar (Granada) (CA)

DiMENSIONES.- つぇ 13,5-15,5 mm; 우 우 15,5-18 mm.

COMPLEMENTOS DE DESCRIPCIÓN.- El macho de esta especie (fig. 30) es sin duda el que presenta una forma general más paralela de todas las especies ibéricas; el pronoto estrecho, escotado en su borde anterior en arco de círculo, de lados en curva regular más convergente hacia delante que hacia atrás, la base bi-sinuosa con los ángulos posteriores más salientes que el lóbulo medio; las márgenes anchas y levantadas, el disco moderadamente convexo con punteado fuerte y denso bastante pubescente; los élitros más del doble de largos que de anchos, muy paralelos en sus dos tercios anteriores, estrechados en su tercio posterior pero no caudiformes, de convexidad transversal moderada así como la declividad posterior; la sutura mediana relevada; cada élitro con dos costillas dorsales bien señaladas, la primera iniciada casi a la base, bastante entera, algo debilitada en la declividad pero llegando hasta la extremidad, la segunda iniciada algo más lejos de la base y cerca de su centro, termina uniéndose a la primera al principio de la declividad o desapareciendo a ese nivel; los intervalos, irregulares (el externo igual a los dos primeros reunidos), con una granulación fina y pubescente (la pilosidad larga y dorada bastante caediza, aunque siempre más o menos presente) en la que destacan gránulos más gruesos y brillantes que a veces están orientados formando relieves longitudinales de aspecto costiforme, particularidad que es mucho más frecuente en las hembras.

El edeago (fig. 32) de $4 \mathrm{~mm}$, con los parámeros casi igual de largos que la falobase, el índice $\mathrm{Pb} / \mathrm{Pa}=1,11$, la silueta parameral ojival no estrechada a la base; el endofalo bastante ensanchado a su base y bastante estrechado en su mitad distal pero de ápex no agudo.

La hembra (fig. 31), de talla mayor y de forma más oval, presenta un pronotum algo más transverso con los ángulos posteriores más salientes hacia atrás; la máxima anchura de los élitros al principio de su tercio posterior; las esculturas tegumentarias son semejantes a las del macho. Como es común en otras especies, los tarsos anteriores y las antenas son más cortos y el diente externo de las protibias está más desarrollado.

El ovipositor (fig. 33) fuerte y largo $(9,5 \mathrm{~mm})$ con índice $\mathrm{L} / 1=1,89$ e índice $\mathrm{lb} / \mathrm{la}=4,66$ : la sinuosidad dorsal de los paraprocta, al principio de la mitad basal del tronco, la extremidad distal de oblicuidad moderada (unos $30^{\circ}$ ) con el ángulo dorsal bien redondeado; los epicolpos con la extremidad distal en curva algo asimétrica, un poco divergentes y con la superficie deprimida y algo deslustrada. La pieza apical (figs. 34-36) presenta una silueta casi recta, nada sinuosa; la fossa analis es estrecha y alargada de bordes paralelos con el fondo cortamente hendido en la extremidad. Los coxita dorsolateralia presentan la pars basalis con la cara dorsal muy ancha, brillante sin punteado perceptible, la cara lateral con un grueso punteado foveolado, pilífero, bastante denso; la pars intermediana rugosa con la pilosidad más persistente; las partes distales lisas: los sclerites vulvaris normalmente esclerotizados. Las coxita apicalia ofrecen un area dorsiapicalis con fina rugosidad mate, la pars lateralis bastante lisa; la cara ventral con puntos de trichobothria a lo largo del area ventriapicalis y en el centro del area intercoxitalis; el area basalis poco profunda y lisa. El scleritus vulvaris medianus normalmente esclerotizado.

Comentarios.- Ningún material típico ha podido ser localizado en el MNHN. La especie fue señalada por primera vez por Rambur en la Plancha XX de su 'Faune Entomologique de l'Andalousie' (Rambur, 1838: pl. XX, fig. 1-2) pero no iba acompañada de una descripción. Ésta fue hecha la primera vez por Pérez Arcas (Pérez Arcas, 1865: 430) y más tarde por Allard. Por esta razón Escalera atribuyó la especie a Pérez Arcas aunque hoy el Código Internacional de Nomenclatura Zoológica ha devuelto la prioridad a Rambur. Por otra parte, de la lectura atenta de la descripción se puede deducir que su autor se refería a la vez a 'Asida hesperica' y a 'Asida hispalensis' y por ello daba Córdoba como localidad típica de hesperica.

DisTRIBUCIÓN GEOGRÁFICA.- Limitada a los alrededores de la ciudad de Granada.

Alphasida (Elongasida) hispalensis (Escalera, 1906) (figs. 37-43)

Asida (Elongasida) hispalensis Escalera, 1906: 309

Elongasida hesperica hispalensis (Escalera): Viñolas \& Cartagena, 2008: 166

Alphasida (Elongasida) hispalensis (Escalera): Soldati, 2008: 128

Locus TYPICUs.- Osuna, Benaocan [Benacazón] (Sevilla), Badajoz.

TIPO EXAminado.- $1 \widehat{\jmath}$ [Sintipo], Benacazón (Sevilla) J. Lauffer Coll Lauffer; MNCN Cat. Tipos $n^{\circ} 12235$; MNCN_Ent n ${ }^{\circ}$ Cat 70788 (MNCN).

Otro material examinado.- 19 , Córdoba. IV.1909, [Escalera] exp. del Museo, Alphasida (Elongasida) hesperica ssp hispalensis Esc. A. Cobos det, MNCN Ent. $\mathrm{N}^{\circ}$ Cat. $70790(\mathrm{MNCN}) ; 1$ 9 , Badajoz, Hispania, Cerrón Albarrán, V.1946, ex Coll. Dr. A. Cobos. Alphasida (Elongasida) hispalensis Esc. A. Cobos det. 1959, Alphasida (Elongasida) hesperica ssp hispalensis Esc., typus comparandus, A. Cobos det.

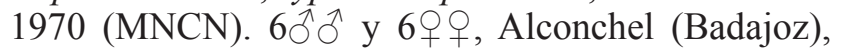




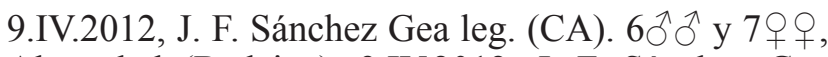
Alconchel (Badajoz), 9.IV.2012, J. F. Sánchez Gea leg. (SG).

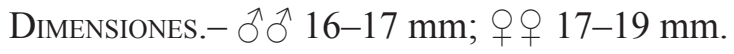

COMPLEMENTOS DE DESCRIPCIÓN.- Especie de talla algo superior a la precedente, también con el cuerpo muy alargado pero menos paralelo y un poco más ancho. El macho (fig. 37) con el pronotum más ancho de márgenes más anchas e igualmente levantadas, los ángulos posteriores agudos y muy prolongados hacia atrás descansando sobre los húmeros, que son rectos y redondeados; los élitros muy débilmente ovales con dos costillas dispuestas como en $A$. hesperica pero solamente la primera entera en su tercio anterior y muy fragmentada después y la segunda enteramente más interrumpida y menos marcada; la granulación del fondo mayor y mucho más pubescente, pero no orientada formando trazos longitudinales.
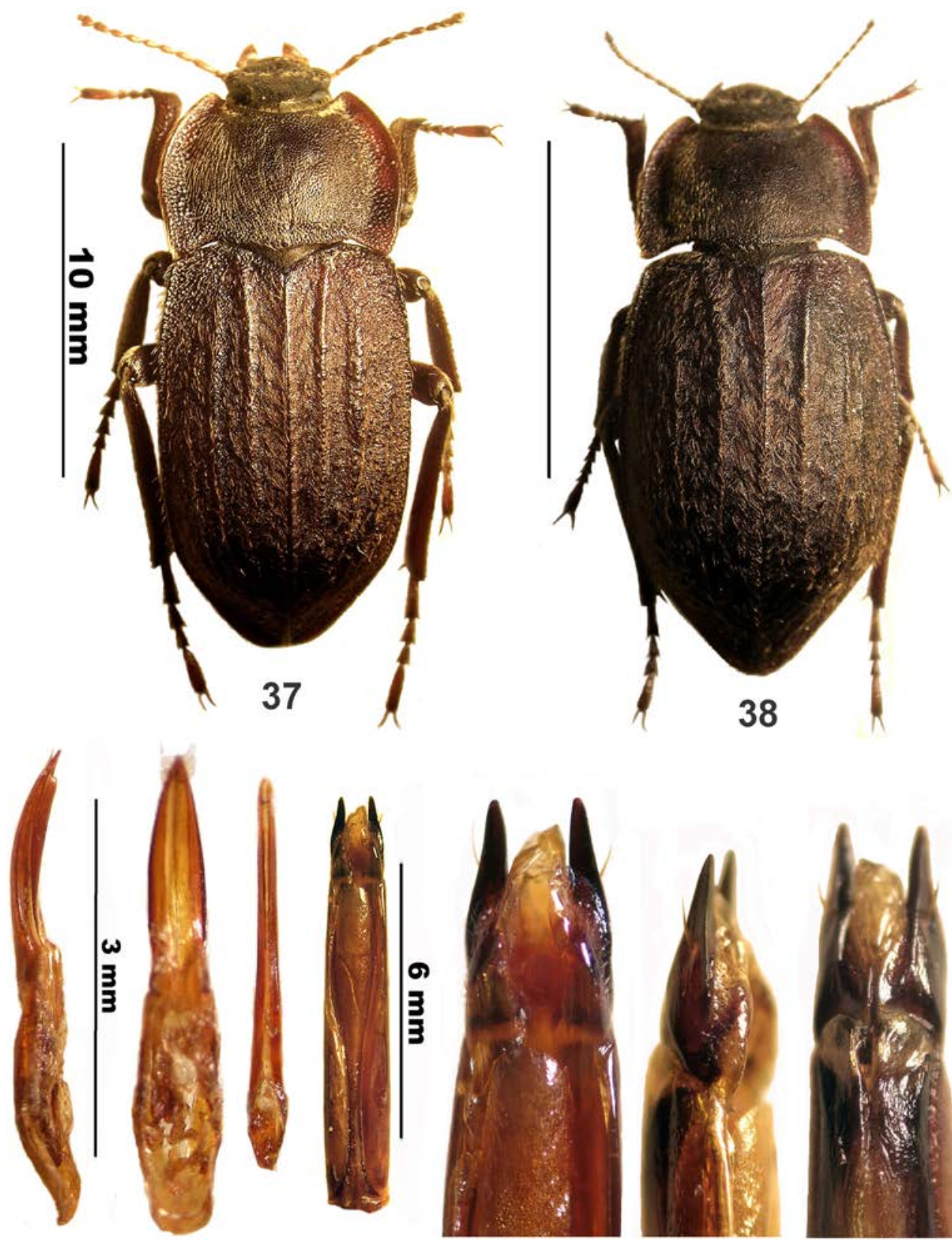

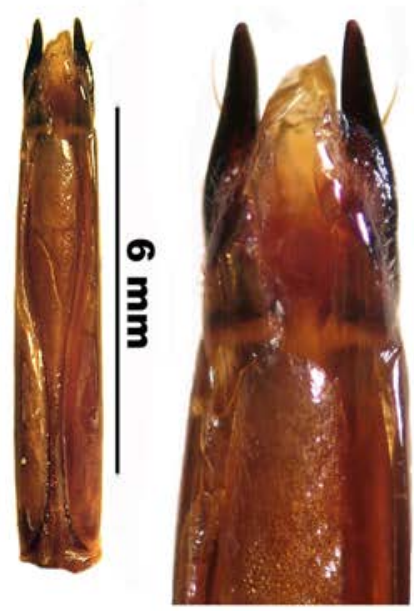

40
41

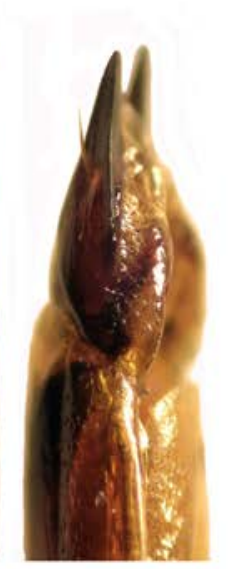

42

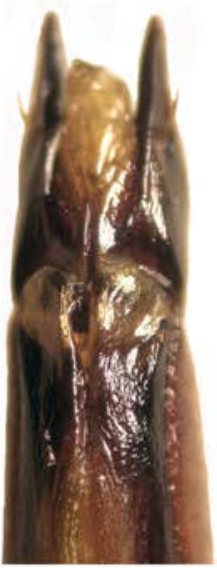

43

Figs. 37-43.- Alphasida (Elongasida) hispalensis (Escalera, 1906): 37, habitus del Sintipo đ̄ MNCN 70788; 38, habitus de la + MNCN 70790; 39, vista lateral del edeago y vista dorsal de la pieza principal y del endofalo: 40, ovipositor, vista dorsal; 41-43, extremidad del mismo en vistas dorsal, lateral y ventral.

Figs. 37-43.- Alphasida (Elongasida) hispalensis (Escalera, 1906): 33, habitus of the ${ }^{1}$ Syntypus MNCN 70788; 38, habitus of the 9 MNCN 70790; 39, side view of aedeagus and dorsal view of principal piece and endophallus; 40, ovipositor, dorsal view; $41-43$, dorsal, lateral and ventral views of ovipositor top. 
El edeago (fig. 39) de 4,5 mm, bastante convexo ventralmente, de parámeros de longitud similar a la de la falobase, el índice $\mathrm{Ph} / \mathrm{Pa}=1,08$; la silueta parameral en ojiva algo estrechada a la base; el endofalo un poco ensanchado a su base, algo estrechado hacia el ápice que es romo.

La hembra (fig. 38) de talla superior, más ancha y más oval, con el pronotum mucho más transversal y la costulación elitral bastante borrada y una pubescencia muy importante, larga y tendida hacia atrás.

El ovipositor (fig. 40) es largo y robusto $(9 \mathrm{a} 10 \mathrm{~mm})$, con índice $\mathrm{L} / \mathrm{l}=2,01 \mathrm{e}$ índice $\mathrm{lb} / \mathrm{la}=4,53$ : la sinuosidad dorsal de los paraprocta se sitúa en la mitad del tronco; la extremidad distal es bastante oblicua; la extremidad de los epicolpos en curva casi simétrica (fig. 43) y la superficie bastante rugosa. La pieza apical (figs. 41-43) es alargada, de silueta algo sinuosa con las extremidades apenas divergentes; la fossa analis ojival alargada. Los coxita dorsolateralia, presentan la pars basalis con la cara dorsal lisa y brillante y la cara lateral con un punteado irregular poco denso, pilífero; la pars intermediana con una granulación más densa y pilosidad persistente; la pars distalis lisa. Los coxita apicalia con el area dorsiapicalis lisa y moderadamente brillante; la pars lateralis algo estriada longitudinalmente con algunos puntos pilíferos dispersos, la fossula gonostyloidis bien marcada con 2-3 largas setae apicalis. La cara ventral con algunos puntos portadores de trichobothria en el area intercoxitalis, las areae basales triangulares y lisas. El scleritus vulvaris medianus normalmente esclerotizado.

COMENTARIOS.- El taxón fue descrito con rango específico pero más tarde ha sido tratado como subespecie de A. hesperica. El aislamiento de estas formas vecinas morfológicamente y la ausencia de elementos intermedios nos hace pensar que se trata probablemente de formas muy estabilizadas y que parece razonable conservar su validez específica.

DistribuCiÓN GEOGRÁFICA.- Localizada en las provincias de Córdoba, Sevilla y Badajoz es el taxón de más amplia distribución y el más occidental del subgénero.

\section{Alphasida (Elongasida) levantina sp. nov. (figs. 44-50) \\ http://zoobank.org/urn:1sid:zoobank.org:act:53D68897-5970- 4A45-9524-A93C06C198A1}

Locus TYPICus.- Totana, San José de la Vega, Alquerías, Librilla (Murcia).

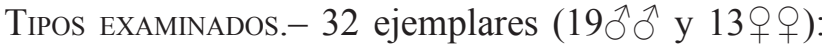
Holotypus d, Totana, Murcia, Hispania, Coll. Dr. Balaguer; [etiqueta blanca manuscrita]: Alphasida (Elongasida) hesperica ssp levantina nov. Holotypus. A. Cobos det. 1985 [etiqueta blanca manuscrita]: Holotipo de Alphasida (Elongasida) levantina PérezVera, Ávila \& Martínez des. 2017 [etiqueta roja impresa]; MNCN_Ent 84541 [etiqueta gris impresa].
Paratypus: $10^{\Uparrow}$ y 19 , Murcia, Totana, Hispania, 6.X.1940, Dr. Balaguer coll [etiqueta blanca manuscrita]; Alphasida (Elongasida) hesperica ssp hispalensis A. Cobos det. 1985 [etiqueta blanca manuscrita]; Paratipo de Alphasida (Elongasida) levantina Pérez-Vera, Martínez \& Ávila des. 2017 [etiqueta roja impresa]; MNCN_Ent 84542 y 84543 [etiqueta gris impresa]. 2 9 9, Alquerías, 28.III.1909 [etiqueta blanca manuscrita]; Alphasida (Elongasida) hesperica ssp hispalensis A. Cobos det. 1985 [etiqueta blanca manuscrita]; Paratipo de Alphasida (Elongasida) levantina Pérez-Vera, Martínez \& Ávila des. 2017 [etiqueta roja impresa]; MNCN Ent. N ${ }^{\circ}$ Cat. 70789 y 110668 [etiquetas grises impresas]. In Coll. Cobos (MNCN). $90^{\lambda} \sigma^{\lambda}$ y 509 , San José de la

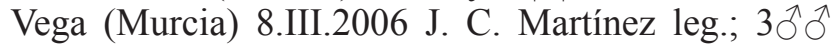
y 19 , Casas Nuevas, Librilla (Murcia) 6.IV.2011 J.

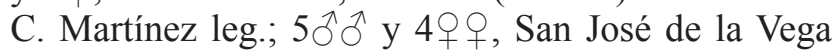
(Murcia) IV.2015 José Fermín Sánchez leg. (SG).

Otro Material (No EXAMINADO).- 10 España, Alicante, Orihuela III.9 Andreu. MNCN_Ent n ${ }^{\circ}$ Cat. 70781 (en préstamo).

Dimensiones.- Holotipo $\curvearrowright 16 \mathrm{~mm}$ de largo; anchura máxima del pronoto $5,7 \mathrm{~mm}$; anchura máxima de los élitros 5,5 mm. Hembras de 15,5 a 16,5 $\mathrm{mm}$ de largo; anchura máxima del pronoto $6 \mathrm{~mm}$; anchura máxima de los élitros 7,7 $\mathrm{mm}$.

DesCRIPCIÓn.- Habitus bastante similar al de Alphasida hesperica con el cuerpo en el macho (fig. 44) muy paralelo, la máxima anchura de los élitros igual a la del pronoto o incluso algo menor, de color marrón oscuro, poco brillante, con pilosidad moderada de color claro; la cabeza transversal con punteado redondo denso, bien marcado; las antenas largas y finas; el pronoto de bordes en curva regular, más convergente hacia delante que hacia atrás, levantados aunque menos que el disco; el borde anterior escotado en arco de círculo, los ángulos anteriores agudos y romos; el borde posterior con doble sinuosidad, los ángulos posteriores agudos, anchos y más salientes hacia detrás que el lóbulo medio; el punteado del disco redondo y bien impreso, denso y pubescente, haciéndose algo granoso en las declividades laterales y sobre las márgenes; éstas más estrechas delante que detrás, donde a nivel de los ángulos aparecen más anchas y menos levantadas. Los élitros con dos costillas dorsales naciendo próximas una de la otra cerca de la base, siguiendo paralelas y casi enteras hasta la declividad posterior donde se descomponen en una serie de tubérculos alineados hasta cerca del ápex; los espacios intercostales están cubiertos por una granulación fina y densa, pubescente, y unos tubérculos alargados, orientados longitudinalmente formando tres o cuatro falsas costillas muy interrumpidas, lisas y muy manifiestas; la sutura aparece igualmente levantada y brillante como una costilla mediana suplementaria. La 


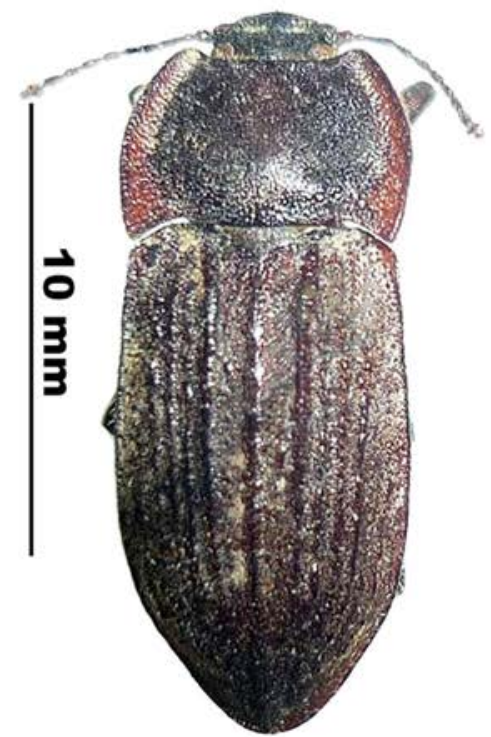

44

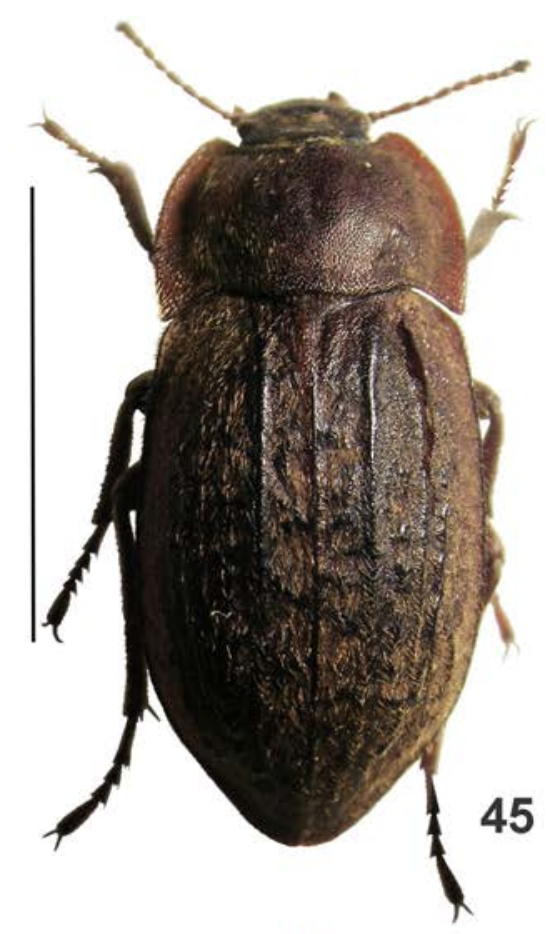

45

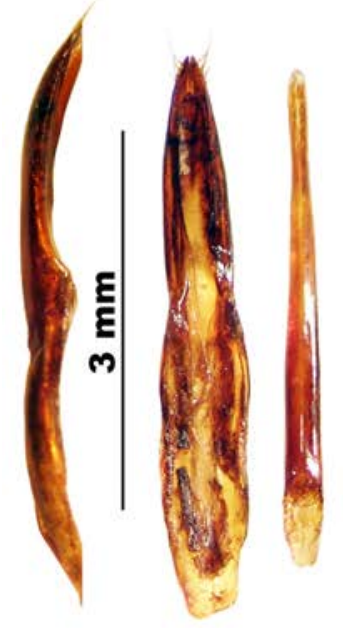

46

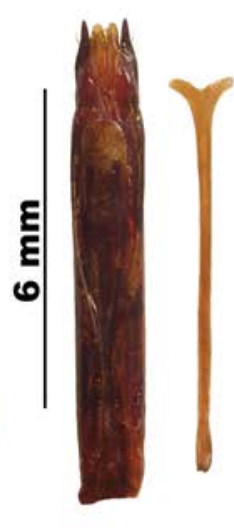

47

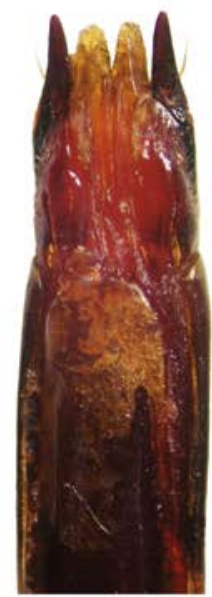

48

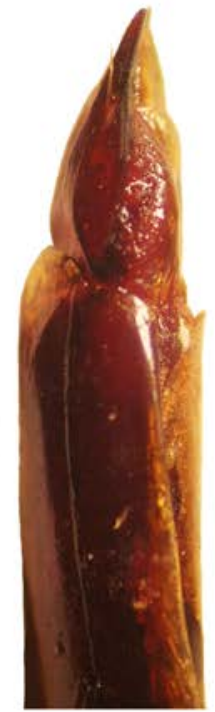

49

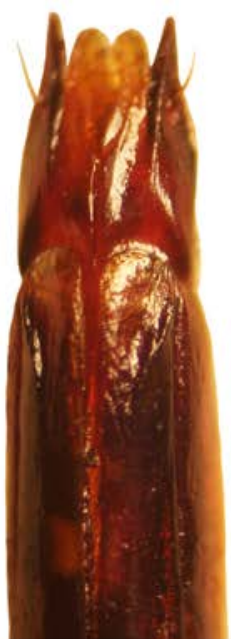

50

Figs. 44-50.- Alphasida (Elongasida) levantina sp. nov.: 44, habitus del Holotipo đ̊̄ MNCN 84541; 45, habitus de un Paratipo $ᄋ$ MNCN 70789; 46, vista lateral del edeago y vista dorsal de la pieza principal y del endofalo: 47, ovipositor, vista dorsal; 48-50, extremidad del mismo en vistas dorsal, lateral y ventral.

Figs. 44-50.- Alphasida (Elongasida) levantina sp. nov.: 44, habitus of the Holotypus MNCN 84541; 45, habitus of a 9 Paratypus MNCN 70789; 46, side view of aedeagus and dorsal view of principal piece and endophallus; 47, ovipositor, dorsal view; 48-50, dorsal, lateral and ventral views of ovipositor top.

cara inferior está cubierta por una granulación fina y pubescente, más dispersa y sobre un fondo estriado longitudinalmente en las propleuras.

El edeago (fig. 46) de 4,5 $\mathrm{mm}$ con los parámeros de igual longitud que la falobase, el índice $\mathrm{Ph} / \mathrm{Pa}=1$. La ojiva parameral regular, los bordes dorsales anchos; el endofalo apenas ensanchado a la base, estrechándose de forma progresiva hasta el ápex que no es agudo.

La hembra (fig. 45) presenta una talla ligeramente superior, el cuerpo más ancho y de forma más oval, las antenas algo más cortas; el pronoto más transverso de márgenes algo más anchas y menos levantadas y los ángulos posteriores más prolongados hacia atrás; los élitros claramente más anchos que el pronoto y las esculturas tegumentarias y la costulación semejantes al macho. El spiculum ventral largo y fino, poco engrosado a la base y netamente bilobulado en su extremidad distal.

El ovipositor (fig. 47) largo y fuerte, de 8,5 a $9 \mathrm{~mm}$ con índice $\mathrm{L} / \mathrm{l}=1,8$ e índice $\mathrm{lb} / \mathrm{la}=4,5$; la sinuosidad dorsal de los paraprocta al principio de la mitad basal del 
tronco, la extremidad distal algo oblicua con el ángulo dorsal redondeado; la extremidad distal de los epicolpos muy redondeada pero algo asimétrica con la parte interna algo más avanzada en sentido distal, la superficie con un area triangular interna rugosa, delimitada por una cresta oblicua partiendo del ángulo externo hacia la línea media. La pieza apical (figs. 48-50) de silueta débilmente curvilínea de extremidades algo divergentes pero muy poco sinuosa; la fossa analis estrechamente alargada con el fondo variablemente hendido longitudinalmente, los sclerites vulvares laterales normalmente esclerotizados; los coxita dorsolateralia con la pars basalis de ancha cara dorsal lisa y brillante, su cara lateral con algunos finos puntos pilíferos y una ancha zona fosulada y pilosidad sensitiva; la pars intermediana de superficie rugosa y pubescente; la pars apicalis fina y lisa; los coxita apicalia con el area dorsiapicalis algo rugosa y brillante; la cara lateral de superficie bastante lisa y algunos puntos a lo largo del borde externo, las fossulae gonostyloidis con varias setae apicalis más o menos aglutinadas; la cara ventral con el area ventriapicalis acanalada, el borde exterior prolongándose con el baculum transversalis, el borde interno diluido en el area intercoxitalis; algunos puntos dispersos portadores de trichobothria, los bordes relevados de la carena mediana lisos y glabros; el scleritus vulvaris medianus normalmente esclerotizado.

COMENTARIOS.- Las tres formas constitutivas del grupo de Alphasida hesperica son sin duda vecinas y localizadas en zonas geográficas bien definidas y diferentes, los detalles característicos de cada una de ellas son igualmente muy constantes y la variabilidad que se pueda apreciar dentro de cada forma se limita prácticamente al tamaño, circunstancia en general ligada a las condiciones nutricionales y medioambientales del individuo durante el periodo pre-imaginal. Creemos por todo ello que estas formas tan estabilizadas deben ser conservadas con rango específico.

DistRIBUCiÓN GEOGRÁFICA.- Región centro-este de la provincia de Murcia y extremo suroeste de la provincia de Alicante.

\footnotetext{
Alphasida (Elongasida) moroderi sp. nov. (figs. 51-57) http://zoobank.org/urn:lsid:zoobank.org:act:934C7D99-49F34273-81A7-7BE2985433E5
}

\section{Locus TYPICUS.- La Encina (Albacete).}

Tipos EXAminados.- Holotypus ồ, La Encina, Albacete, 13.IV.1917, Moroder leg [etiqueta manuscrita]; Alphasida (Elongasida) moroderi nov. in litt. Cobos [etiqueta manuscrita]; MNCN_Ent. 107302 [etiqueta gris impresa]; Holotypus Alphasida (Elongasida) moroderi nov. sp. Pérez-Vera \& Ávila det. 2015 [etiqueta roja impresa] (MNCN).

Paratypus: $10 \hat{\text { y }} 1$ 1 9 : idem holotypus; MNCN_Ent. 107303 y 107304 [etiquetas grises impresas]. 1 + ídem holotypus; Alphasida (Elongasida) rectipennis ssp calumniata Esc. A. Cobos det. 1970 [etiqueta blanca manuscrita]; MNCN_Ent. 195057 [etiqueta gris impresa] (MNCN).

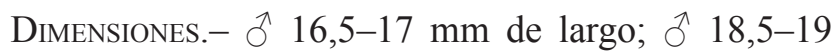
$\mathrm{mm}$ de largo.

DESCRIPCIÓN.- El cuerpo negro y bastante mate de moderada convexidad transversal pero con la declividad posterior muy señalada terminada en un ápex caudiforme ligeramente relevado; los élitros con tres pliegues costales muy bajos, pero perceptibles, cubiertos de la misma estructura granular del fondo pero no constituidos por una serie longitudinal de gránulos. El macho (fig. 51) de cabeza transversal, punteada densamente con el surco clípeo-frontal bien marcado y antenas finas y largas; el pronoto poco transverso de márgenes poco levantadas de bordes finos; el borde posterior casi truncado con los ángulos casi rectos pero más salientes hacia atrás que la parte central; el punteado finamente granular, muy denso; los élitros cubiertos de una fina granulación bastante densa, con pilosidad clara no muy larga; el ápex muy caudiforme de márgenes algo ensanchadas y levantadas. La cara inferior es fina y densamente granulosa y moderadamente pubescente, la granulación es menos densa en el mentón y sobre las falsas epipleuras.

El edeago (fig. 53) de 4,2 $\mathrm{mm}$ con los parámeros casi igual de largos que la falobase, el índice $\mathrm{Ph} / \mathrm{Pa}=1.08$; la silueta parameral ojival con la extremidad ligeramente espatulada y totalmente plana ya que los rebordes dorsales se terminan un poco antes del ápex; el endofalo de base ancha con la mitad distal netamente aplastada transversalmente.

La hembra (fig. 52) mucho más transversal pero de esculturas muy similares al macho; el pronoto considerablemente más transverso, con los ángulos posteriores algo agudos, anchos y más prolongados hacia atrás.

El ovipositor (fig. 54) largo y robusto de $9,3 \mathrm{~mm}$, con índice $\mathrm{L} / \mathrm{l}=1,99$ e índice $\mathrm{lb} / \mathrm{la}=4,59$; la sinuosidad de los paraprocta en el centro del tronco, la extremidad superior fuerte y muy redondeada, la cara lateral cubierta por una fina granulación muy dispersa pero muy manifiesta; la extremidad de los epicolpos muy avanzada en sentido distal y muy oblicuamente redondeada hacia los lados y hacia la línea media, apareciendo así ligeramente divergente. La pieza apical (figs. 55-57) de contorno débilmente bi-sinuoso y extremidades algo divergentes y recurvadas en sentido dorsal; la fossa analis muy estrecha y alargada de fondo hendido longitudinalmente; los coxita dorsolateralia con la pars basalis de cara dorsal punteada y brillante y cara lateral finamente rugosa; la pars intermediana de rugosidad similar a la pars basalis, más pubescente; los coxita apicalia con el area dorsiapicalis rugosa y mate, la cara lateral lisa con una finísima granulación muy dispersa que se extiende a la zona ventral y a las areae basalis que aparecen muy ampliamente excavadas; los sclerites vulvaris en conjunto normalmente esclerotizados. 

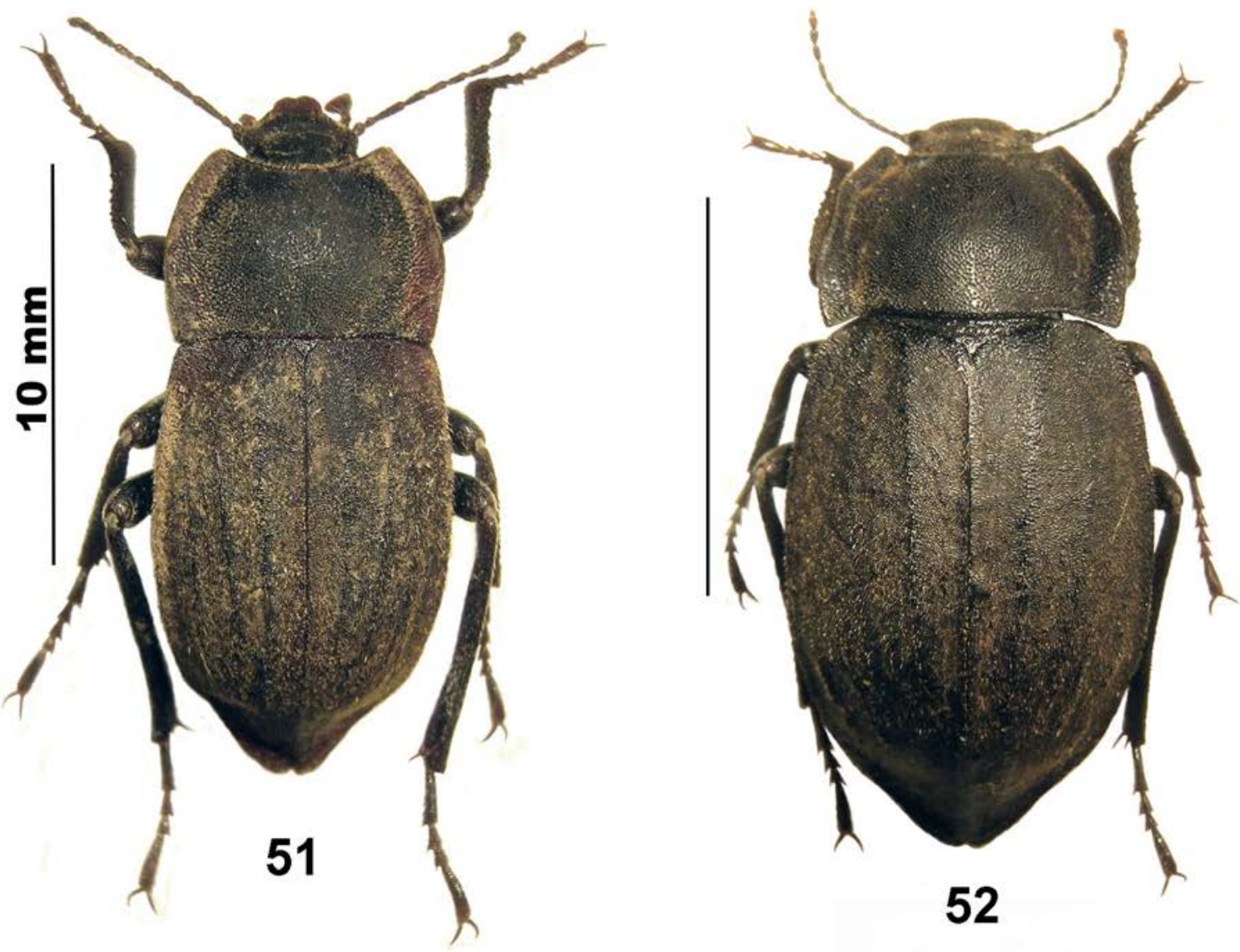

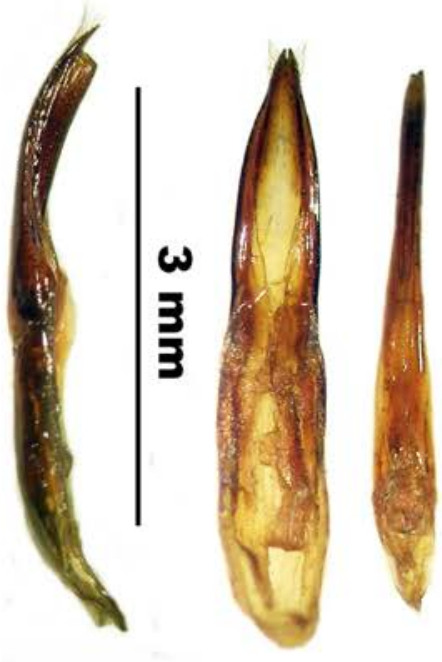

53

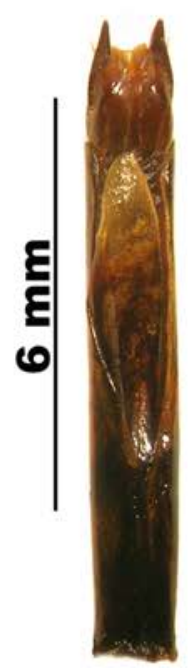

54

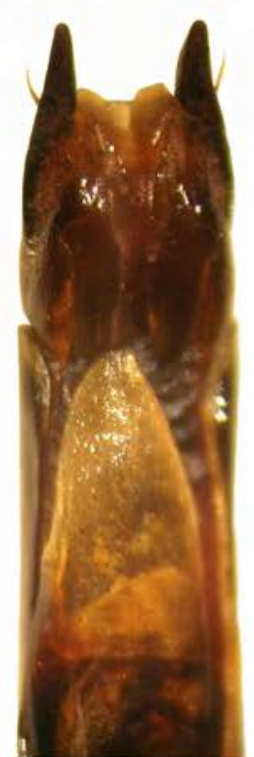

55

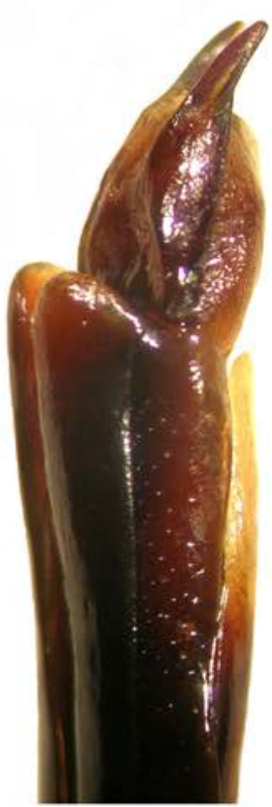

56

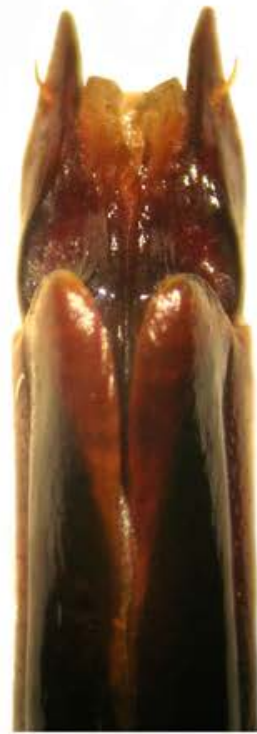

57

Figs. 51-57.- Alphasida (Elongasida) moroderi sp. nov.: 51, habitus del Holotipo ð̊ MNCN 107302; 52, habitus del Paratipo $ᄋ$ MNCN $107304 ; 53$, vista lateral del edeago y vista dorsal de la pieza principal y del endofalo: 54, ovipositor, vista dorsal; 55-57, extremidad del mismo en vistas dorsal, lateral y ventral.

Figs. 51-57.- Alphasida (Elongasida) moroderi sp. nov.: 51, habitus of the Holotypus MNCN 107302; 52, habitus of the $ᄋ$ Paratypus MNCN 107304; 53, side view of aedeagus and dorsal view of principal piece and endophallus; 54, ovipositor, dorsal view; 55-57, dorsal, lateral and ventral views of ovipositor top.

COMENTARIO.- La especie está relacionada con la especie Alphasida calumniata y ofrece las diferencias morfológicas señaladas de manera constante, lo que unido a los detalles discriminativos encontrados en las genitalia de ambos sexos, apunta al reconocimiento de dos especies válidas. 
DisTRIBUCIÓN GEOGRÁFICA.- Región suroriental de la provincia de Albacete, muy cerca del límite con la provincia de Alicante.
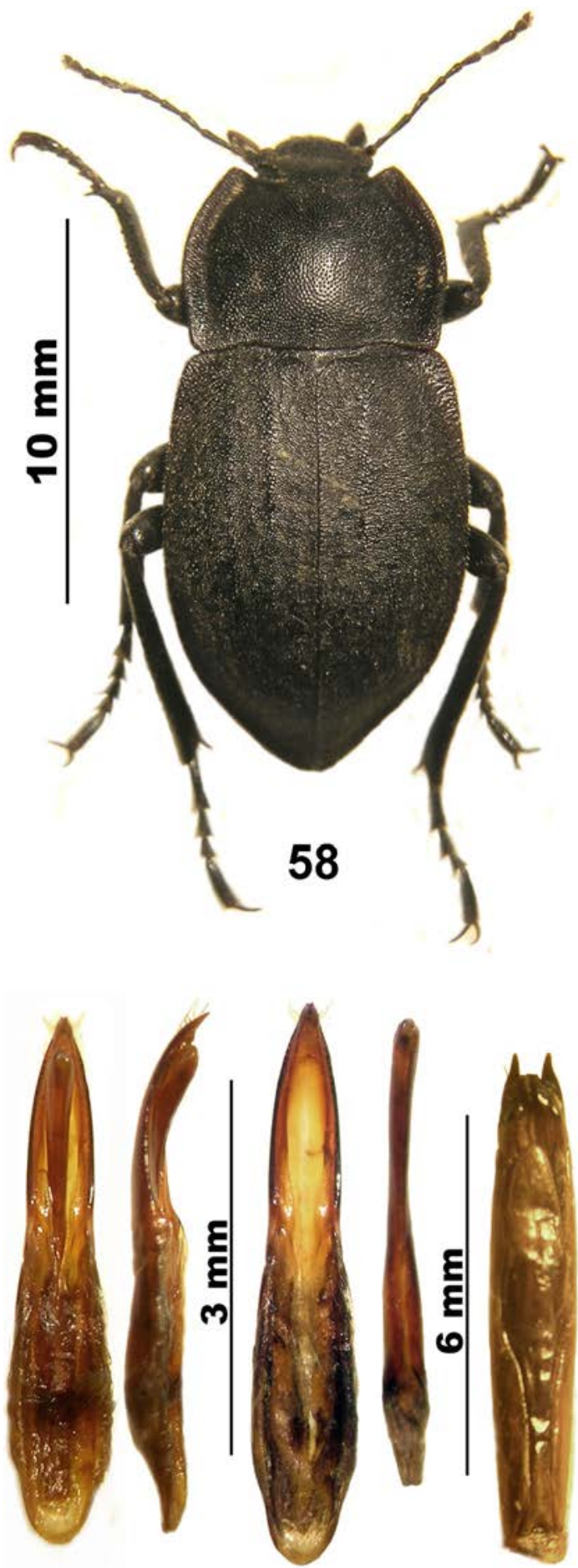

60

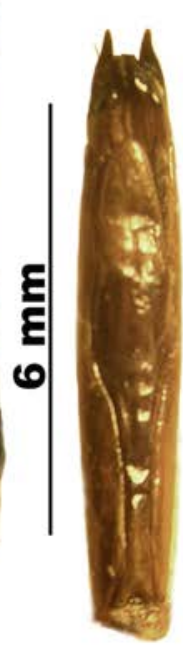

61
Alphasida (Elongasida) rectipennis Escalera, 1906 (figs. 58-64)

Asida (Elongasida) rectipennis Escalera, 1906: 312

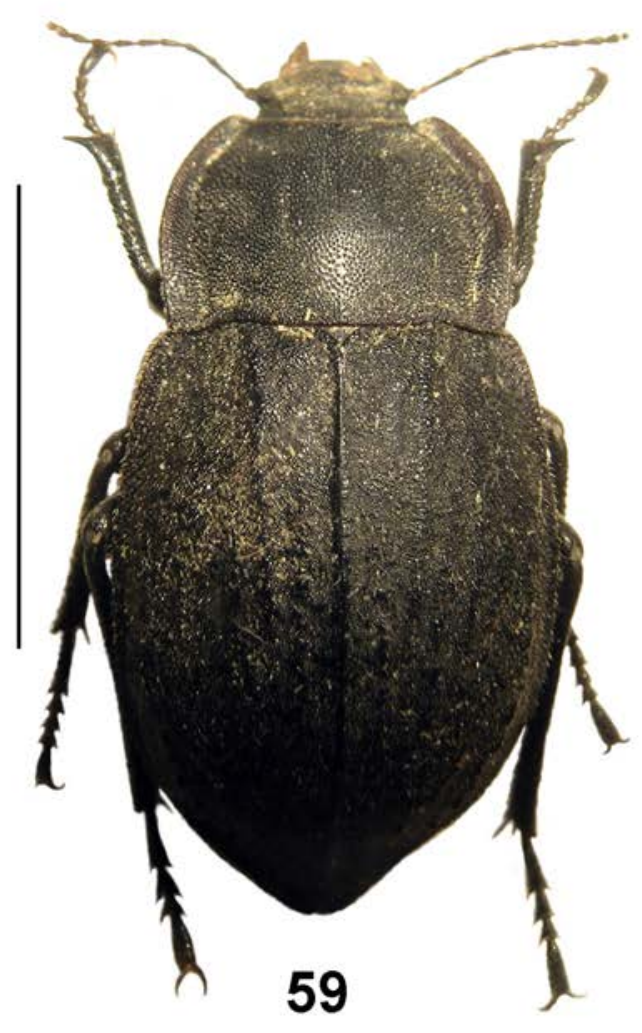

Figs. 58-64.- Alphasida (Elongasida) rectipennis (Escalera, 1906): 58, habitus del Lectotipo $\lambda$ MNCN 71410; 59, habitus del Paralectotipo + MNCN 71413; 60, vistas dorsal y lateral del edeago y vista dorsal de la pieza principal y del endofalo: 61 , ovipositor, vista dorsal; 62-64, extremidad del mismo en vistas dorsal, lateral y ventral.

Figs. 58-64.- Alphasida (Elongasida) rectipennis (Escalera, 1906): 58, habitus of the Lectotypus MNCN 71410; 59, habitus of the $P$ Paralectotypus MNCN 71413;60, dorsal and side views of aedeagus and dorsal view of principal piece and endophallus; 61 , ovipositor, dorsal view; 62-64, dorsal, lateral and ventral views of ovipositor top. 
Elongasida aleonensis rectipennis (Escalera): Viñolas \& Cartagena, 2008: 169

Alphasida (Elongasida) rectipennis (Escalera): Soldati, 2008: 128

Locus TYPICUS.- Huércal Overa, Tíjola (Almería), Galera (Granada) según la descripción original (Escalera, 1906) y de acuerdo con el artículo 73.2.3 (ICZN, 1999); después de la siguiente designación de Lectotypus, la localidad tipo es solamente «Tíjola (Almería)», de acuerdo con el artículo 76.2 del Código (ICZN, 1999).

Tipos eXAminados.- Lectotypus (presente designación): Tíjola (Almería), Escalera 1900 [etiqueta blanca impresa]; Sintipo, MNCN Cat. Tipos no 2190 [etiquetas rojas impresas]; MNCN_Ent. 71410 [etiqueta gris impresa] (MNCN); Paralectotypus: $2 \widehat{\jmath}$ y 1 , Tíjola (Almería) Escalera coll; MNCN_Ent. 71411,71412 y 71414 [etiquetas grises impresas]; 1 , Galera (Granada) Schramm coll; MNCN_Ent. 71413 [etiqueta gris impresa] (MNCN).

Otro material examinado. $-2 \hat{\jmath} \widehat{\jmath}$ y $2 q+$ La Sagra (Granada), Lorca (Murcia), Tíjola (Almería), (MNCN); 7 ejemplares de los dos sexos: 3 Lorca (Murcia), 2 Cantoría (Almería), 1 Tíjola (Almería),

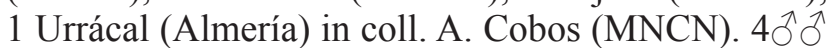
y $3 ㅇ$, Barranco del Espartal, Baza (Granada), entre 1991 y 1992, F. S. Piñero leg. (CA).

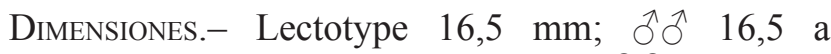
$17,5 \mathrm{~mm}$ (media $17,33 \mathrm{~mm}$ de long); 우우 16,5 a 20 $\mathrm{mm}$ (media $18,7 \mathrm{~mm}$ de long).

Complementos De Descripción.- El macho (fig. 58) presenta un cuerpo negruzco como en Alphasida alonensis pero muy mate, sin el brillo propio de esta última especie. El protórax, de márgenes poco anchas y bien levantadas, con los bordes poco convergentes hacia atrás, los ángulos posteriores en general rectos y no salientes, no recubriendo los hombros y tomando nacimiento muy por dentro del canal marginal, el lóbulo mediano truncado y nada saliente, el conjunto del borde posterior casi recto; los élitros alargados y paralelos, acuminados con la declividad posterior bien señalada.

El edeago (fig. 60) con buena convexidad ventral, los parámeros casi tan largos como la falobase, el índice $\mathrm{Ph} / \mathrm{Pa}=1,06$; la silueta parameral estrechamente ojival las bandas de refuerzo dorsales poco anchas, estrechándose hacia la extremidad para desaparecer totalmente antes del ápex de forma que este aparece muy aplanado; el endofalo algo plano a la base, estrechado después hasta el centro y engrosado y redondeado a la extremidad.

La hembra (fig. 59) de talla algo superior y más ancha, es semejante en el resto al macho.

El ovipositor (fig. 61) robusto con el índice L/1 = 2,3 y el índice $\mathrm{lb} / \mathrm{la}=4,45$ : la sinuosidad dorsal de los paraprocta situada en el centro de la pieza basal, la extremidad distal oblicua y muy redondeada; la de los epicolpos regularmente redondeada, de superficie lisa y brillante. La pieza apical (fig. 62-64) de silueta uniformemente curvilínea en sus dos tercios proximales con las extremidades afiladas y un poco divergentes; la fossa analis estrecha y alargada con el fondo ampliamente hendido; los sclerites vulvaris laterales, de color marrón oscuro, un poco rugosos y bien esclerotizados; los coxita dorsolateralia con la cara dorsal de la pars basalis ancha y rugosa en la mitad proximal y lisa y brillante después, la cara lateral con punteado fuerte y denso, pilífero, que es casi foveolado en el borde ventral; la pars intermediana de superficie rugosa y pubescente; la pars distalis lisa y brillante; los coxita apicalia con el area dorsiapicalis rugosa y poco brillante; la pars lateralis con punteado fino $\mathrm{y}$ disperso, algunos puntos pilíferos a lo largo del borde externo, la fossula gonostyloidis bastante ancha y poco profunda, con dos o tres setae apicalis adheridas entre ellas; la cara ventral con el area ventriapicalis acanalada con punteado disperso; los bordes de la carena mediana relevados, lisos y glabros, muy prolongados hacia la extremidad; gruesos puntos dando nacimiento a trichobothria, dispersos en el area intercoxitalis y en las areae basales, que aparecen bien hundidas; el scleritus vulvaris medianus poco desarrollado.

DistribuCión GeOgRÁfiCA.- Esta especie es relativamente frecuente en la zona noroccidental de la provincia de Almería y en la vecina fosa de Guadix-Baza en la provincia de Granada.

Alphasida (Elongasida) rufomarginalis (Escalera, 1906) (figs. 65-71)

Asida (Elongasida) rufomarginalis Escalera, 1906: 310

Elongasida rufomarginalis (Escalera): Viñolas \& Cartagena, 2008: 167

Alphasida (Elongasida) rufomarginalis (Escalera): Soldati, 2008: 128

Locus TYPICUS.- Almería.

TIPOS EXAMINADOS.- Lectotypus (presente designación): Almería, Ehlers! [etiqueta blanca manuscrita]; Sintipo, MNCN Cat. Tipos no 2191 [etiquetas rojas impresas]; MNCN_Ent. 71416 [etiqueta gris impresa]; Lectotypus de Asida (Elongasida) rufomarginalis Escalera, 1906. Pérez-Vera \& Ávila des. 2015 [etiqueta roja impresa] (MNCN). Paralectotypus: $2 \widehat{\jmath} \widehat{\partial}$ y 1ㅇ: idem lectotypus, MNCN_Ent. 71415, 71417 y 71418 [etiquetas grises impresas] (MNCN).

Otro MATERIAL EXAMINADO.- 44 ejemplares de los dos sexos: 2 Alhama (Almería) 23.III.61, 30 Barranco de la Molineta (Almería) 6-13.XI.60, 6 Campo de Dalías

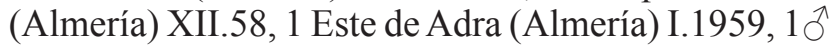
y 1 ㅇ Tabernas (Almería) España 9.XII.1984) in. Coll. Cobos (MNCN); $1 \delta^{\Uparrow}$ y 1․ Argamasón (Almería), 

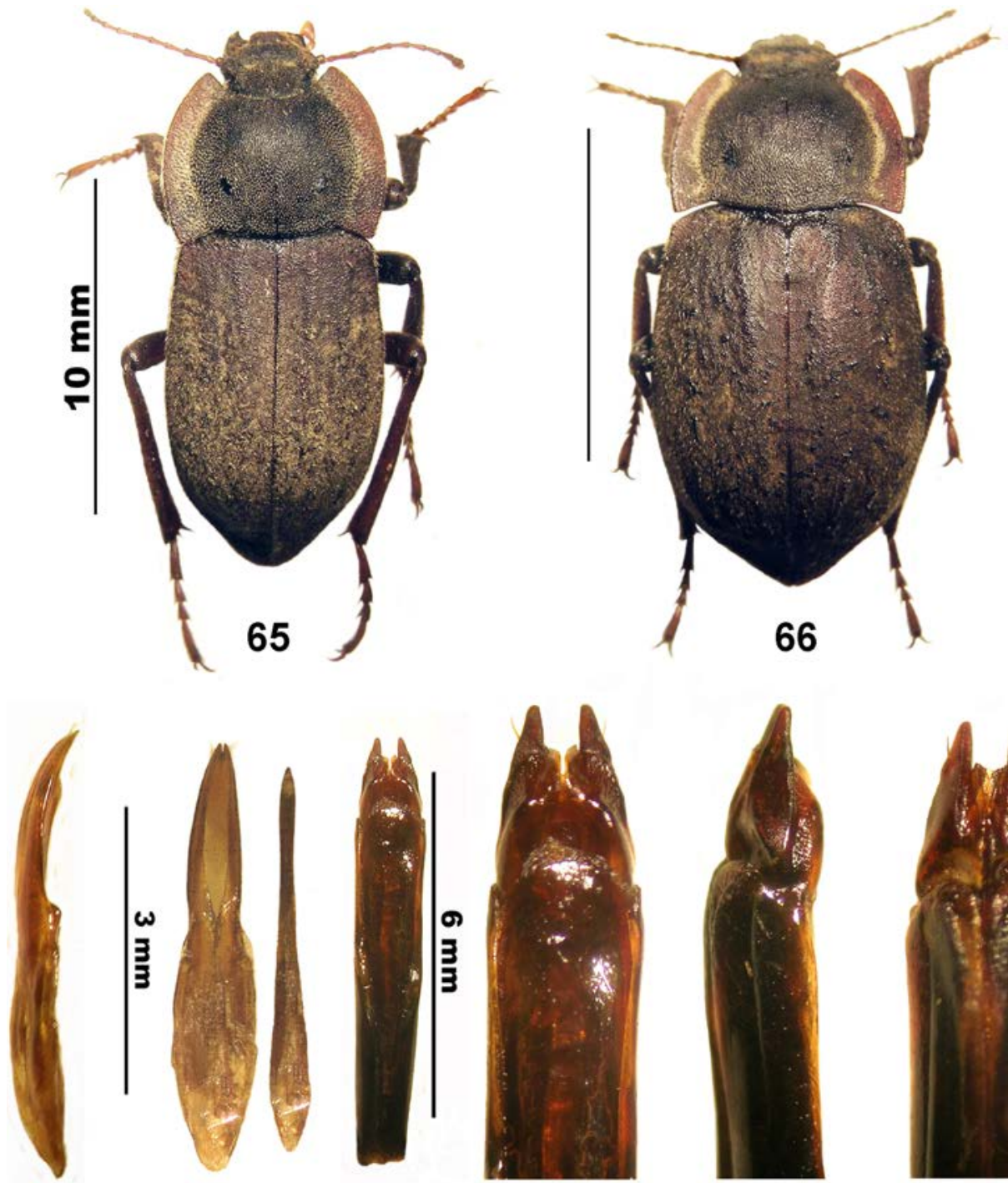

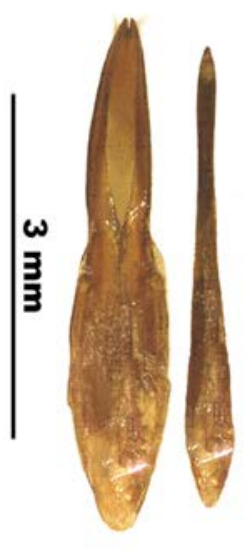

67

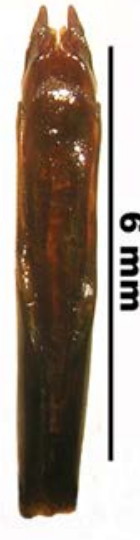

68

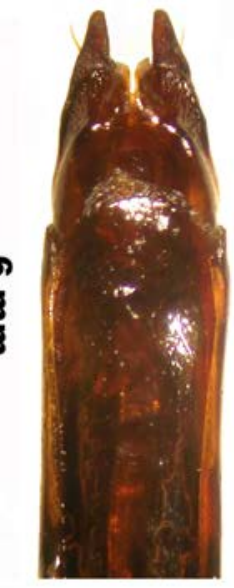

69

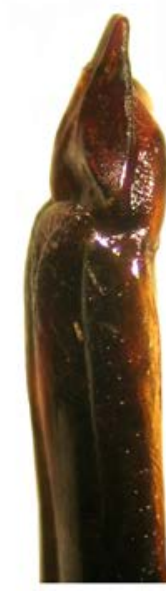

70

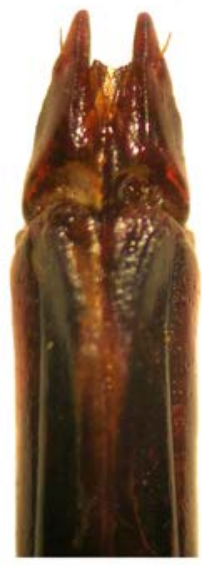

71

Figs. 65-71.- Alphasida (Elongasida) rufomarginalis (Escalera, 1906): 65, habitus del Lectotipo $\overbrace{}^{1}$ MNCN 71417; 66, habitus del Paralectotipo 9 MNCN 71416; 67, vista lateral del edeago y vista dorsal de la pieza principal y del endofalo: 68, ovipositor, vista dorsal; 69-71, extremidad del mismo en vistas dorsal, lateral y ventral.

Figs. 65-71.- Alphasida (Elongasida) rufomarginalis (Escalera, 1906): 65, habitus of the Lectotypus MNCN 71417; 66, habitus of the 9 Paralectotypus MNCN 71416; 67, side view of aedeagus and dorsal view of principal piece and endophallus; 68 , ovipositor, dorsal view; 69-71, dorsal, lateral and ventral views of ovipositor top.

11.XI.2011, J. C. Martínez leg (CA); 1, Espartal de Nijar (Almería), 1.XII.1991, J. M. Ávila (CA).

DiMENSIONES.- ठึ 15,5 a $16 \mathrm{~mm}$; 우 16 a $17 \mathrm{~mm}$ de largo.

COMPLEMENTOS DE DESCRIPCIÓN.- Los machos (fig. 65) presentan un cuerpo alargado, paralelo, poco convexo y deprimido, la cabeza de palpos maxilares normales, el pronoto ancho de disco normalmente convexo y márgenes bastante anchas y algo levantadas, finas y ligeramente translúcidas, de color rojizo; los élitros con los húmeros bastante redondeados, paralelos en sus dos tercios anteriores y poco acuminados detrás, sin costillas, únicamente la parte proximal de la primera dorsal perceptible por una granulación un poco más acusada.

El edeago (fig. 67), moderadamente convexo, con los parámeros casi tan largos como la falobase aunque más estrechos, el índice $\mathrm{Ph} / \mathrm{Pa}=1,07$; la silueta parameral estrechamente ojival algo estrechada al nivel de los tubérculos dorsales; el endofalo ensanchado a la base y progresivamente afilado hasta el ápex.

La hembra (fig. 66), de talla ligeramente superior y más ancha con el pronoto de bordes más convergentes hacia delante y menos hacia atrás que en el macho; los élitros con la primera costilla dorsal más marcada, acompañada de alineaciones longitudinales más significativas de gránulos tuberculoides. 
El ovipositor (fig. 68) es bastante robusto con índice $\mathrm{L} / 1=2,2$ e índice $\mathrm{lb} / \mathrm{la}=4,23$; la sinuosidad dorsal de los paraprocta en el centro del tronco, ligeramente desplazada hacia la base; la extremidad distal troncada recta; los epicolpos con la extremidad redondeada y la superficie deslustrada sobre una larga zona triangular rugosa. La pieza apical (figs. 69-71) de silueta uniformemente curvilínea, de extremidades no divergentes; la fossa analis ojival con el fondo brevemente hendido, los sclerites vulvaris laterales normalmente esclerotizados; los coxita dorsolateralia con la pars basalis de cara dorsal lisa y brillante y la cara lateral cubierta por un fuerte y denso punteado pilífero; la pars intermediana de superficie granulosa y pubescente; la pars distalis estrecha y lisa; los coxita apicalia con el area dorsiapicalis rugosa y brillante; la pars lateralis muy finamente punteada con una fila de puntos pilíferos a lo largo del borde externo, la fossula gonostyloidis con dos o tres setae apicalis aglutinadas; la cara ventral con el area ventriapicalis acanalada, el area intercoxitalis con una elevación longitudinal lisa y glabra de cada lado de la sutura mediana y numerosos puntos portadores de trichobothria sobre el resto de la superficie, incluidas las areae basales; el scleritus vulvaris medianus es poco manifiesto

DistribuCión GEOGRÁfiCA.- La especie se sitúa en la zona suroriental de la provincia de Almería, en la región del cabo de Gata.

Alphasida (Elongasida) silvestrei (Escalera, 1922) comb. nov. (figs. 72-78)

Asida silvestrei Escalera, 1922: 174

Asida (Pseudoelongasida) silvestrei Escalera: Soldati, 2008: 139

Alphasida (Glabrasida) dendriticosta Pérez-Vera \& Ávila, 2012a: 20 — Pérez-Vera \& Ávila, 2012b: 297

Alphasida (Pseudoelongasida) silvestrei (Escalera): Pérez-Vera, 2012: 124 — Pérez-Vera \& Ávila, 2012c: 165

Locus TYPIcus.- Alcázar (Ksar-el-Kbir) (Marruecos).

Tipos EXAminados.- $1 \hat{\jmath}$ Lectotypus (presente designación): Marruecos l'Ksar [etiqueta manuscrita]; Pseudoelongasida silvestrei Esc [etiqueta manuscrita de Escalera]; Sintipo de Asida (Pseudoelongasida) silvestrei Escalera, 1922 [etiqueta roja impresa]; MNCN Cat. Tipos $n^{\circ} 2171$ [etiqueta roja impresa]; MNCN_Ent 69203 [etiqueta gris impresa] (MNCN). Paralectotypus: 1 i idem lectotipo; MNCN_Ent 69654 [etiqueta gris impresa] (MNCN).

Alphasida (Glabrasida) dendriticosta Pérez-Vera \& Ávila, 2012: Holotypus + Marruecos, Arbaoua, Rharb 15.V.38 G. Schramm [etiqueta manuscrita]; Alphasida cossyphoides Antoine A. Cobos det. 1959 [etiqueta manuscrita]; Holotipo de Alphasida (Glabrasida) dendriticosta Pérez-Vera \& Ávila, 2012 [etiqueta roja impresa] $=$ Asida (Pseudoelongasida) silvestrei Escalera, 1922 Pérez-Vera det. 10.10.2012 [manuscrito]; MNCN Cat, Tipos $\mathrm{n}^{\circ} 2349$ [etiqueta roja impresa]; MNCN_Ent 69567 [etiqueta gris impresa] (MNCN). Paratypus o, ídem holotipo; MNCN_Ent 69603 [etiqueta gris impresa] (MNCN).

Otro Material eXAminado.- 10 Marruecos Arbaoua Maroc IV.27 Antoine, Asida silvestrei Esc. Antoine det. MNCN Ent 195246; 1 9 Arbaoua, Rharb, 15-V38, Schramm MNCN_195247; 10 Lalla Mimouna, Marruecos 20.IV.58 Kocher-Pruja (in coll Cobos $\mathrm{MNCN}) ; 49$ y $4 \hat{\bigcirc}$ Marruecos Arbaoua (Maroc) Antoine (MNCN)

\section{DiMENSIONES.- $ぇ \widehat{~} 11 \mathrm{a} 12 \mathrm{~mm}$ 우 $13-14 \mathrm{~mm}$.}

Complementos DE DESCRIPCIÓN.- Las descripciones originales de las especies norteafricanas constituyentes del subgénero Pseudoelongasida y que nosotros incorporamos aquí al subgénero Elongasida, habían sido bastante explicitas, tanto la de Asida silvestrei (Escalera, 1922: 174) como la de Asida tenuecostata (Fairmaire, 1880a: 190 y 1880b: 250). Ya fueron transcritas y ampliamente comentadas en el trabajo en el que transferimos el subgénero Pseudoelongasida al género Alphasida (Pérez-Vera, 2012) y en la Monografía sobre los Asidini marroquíes (Pérez-Vera \& Ávila, 2012c). Aquí insistiremos en las similitudes $\mathrm{y}$ en las diferencias fundamentales de las especies africanas con las especies ibéricas. Desde el punto de vista morfológico existe una clara relación entre las primeras y el grupo de Alphasida hesperica. El macho de Alphasida silvestrei (fig. 72) es más ancho y menos alargado que el de $A$. hesperica, pero de igual forma paralela, con el pronoto poco convexo, de bordes poco curvos y poco convergentes hacia delante y hacia atrás, la base débilmente bi-sinuosa, tan ancha como la base de los élitros; el punteado muy débilmente alargado y bastante denso haciéndose casi foveolado y algo granuloso sobre las márgenes; los élitros con tres costillas finas y enteras, las dos primeras, dorsales, naciendo de la base, algo convergentes entre ellas, alejadas de la sutura y uniéndose al principio de la declividad posterior en una sola que se continua hasta el ápex; la tercera costilla, lateral, nace lejos de la base y se sigue paralela a las precedentes para unirse con ellas cerca de la extremidad posterior; los intervalos, de los cuales el primero es sensiblemente más ancho que los otros, cubiertos por una fina y densa granulación; tanto el pronoto como los élitros con una muy corta pubescencia clara muy caediza y poco observable.

El edeago (fig. 74) de 4,5 mm presenta los parámeros algo más cortos y más estrechos que la falobase, el índice $\mathrm{Ph} / \mathrm{Pa}=1,2 ;$ el endofalo nada ensanchado a la base, fuerte y prácticamente cilíndrico con la extremidad redondeada.

La hembra (fig. 73), de cuerpo menos alargado, más ancho y más convexo, presenta a veces un aspecto general que la asemeja a algunas Glabrasida norteafricanas, lo que nos llevó, junto con la inexperiencia 

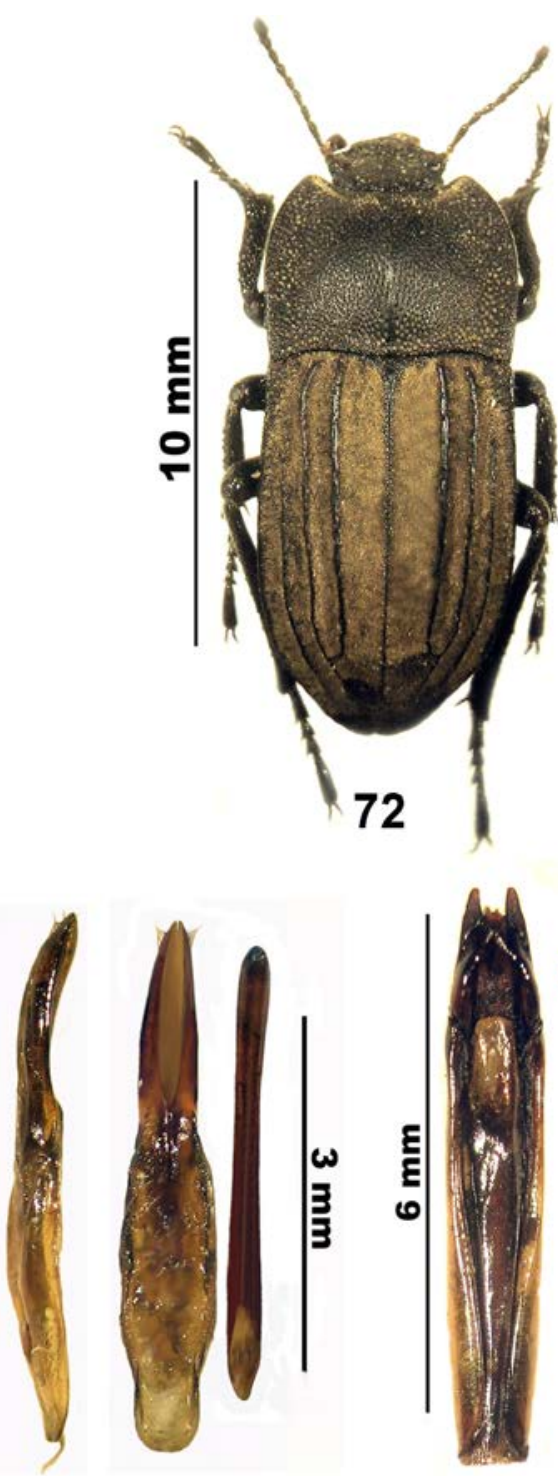

74

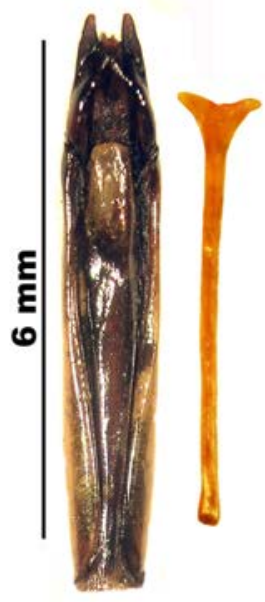

75

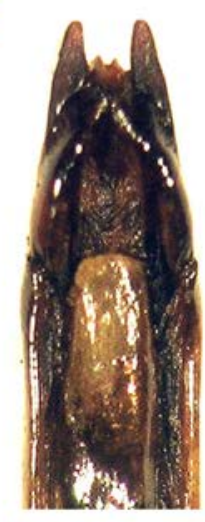

76

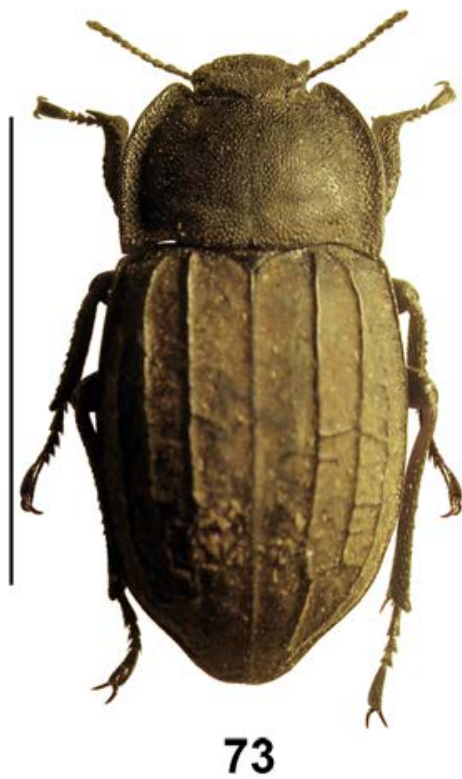

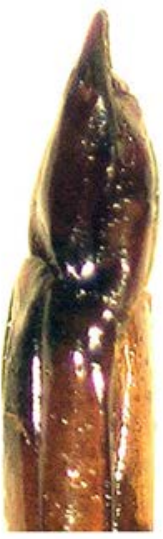

77

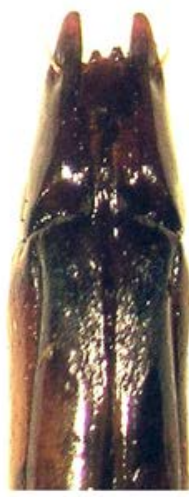

78

Figs. 72-78.- Alphasida (Elongasida) silvestrei (Escalera, 1922): 72, habitus del đ̊ MNCN 53209; 73, habitus del Paralectotipo + MNCN 69654; 74, vista lateral del edeago y vista dorsal de la pieza principal y del endofalo: 75, ovipositor, vista dorsal; 76-78, extremidad del mismo en vistas dorsal, lateral y ventral.

Figs. 72-78.- Alphasida (Elongasida) silvestrei (Escalera, 1922): 72, habitus of the ${ }^{7}$ MNCN 53209; 73, habitus of the $q$ Paralectotypus MNCN 69654; 74, side view of aedeagus and dorsal view of principal piece and endophallus; 75, ovipositor, dorsal view; 76-78, dorsal, lateral and ventral views of ovipositor top.

del momento, a la confusión en la que fue descrita Alphasida dendriticosta Pérez-Vera y Ávila, 2012. El error fue corregido poco después y la sinonimia establecida (Pérez-Vera \& Ávila, 2012b: 297). Las esculturas tegumentarias en ambos sexos son muy similares y solo habría que señalar la mayor tendencia a la formación de finas ramificaciones costales en las hembras.

El ovipositor (fig. 75) robusto, de $7 \mathrm{~mm}$ de largo, con índice $\mathrm{L} / 1=1,86$ e índice $1 \mathrm{~b} / \mathrm{la}=3,4$ : la sinuosidad dorsal de los paraprocta, a la base misma del tronco, la extremidad distal de oblicuidad moderada (unos $25^{\circ}$ ) con los ángulos muy poco redondeados; la superficie de los paraprocta así como la del proctiger cubierta de un punteado fino y disperso; los epicolpos con las extremidades distales truncadas, un poco oblicuamente hacia afuera, apareciendo así un poco divergentes y con la superficie algo rugosa y deslustrada. La pieza apical (fig. 76-78) presenta una silueta muy débilmente curvilínea, apenas sinuosa; la fossa analis es claramente ojival con el fondo muy cortamente hendido en la extremidad. Los coxita dorsolateralia presentan la pars basalis con la cara dorsal ancha, brillante y sin punteado perceptible, la cara lateral con un punteado moderado, pilífero, poco denso; la pars intermediana ligeramente rugosa; las partes distales lisas; los sclerites vulvaris laterales cortos y normalmente esclerotizados. Las coxita apicalia ofrecen un area dorsiapicalis con fina rugosidad algo brillante, 
la pars lateralis bastante lisa con punteado fino $\mathrm{y}$ disperso; la cara ventral con puntos de trichobothria uniformemente distribuidos a lo largo del area
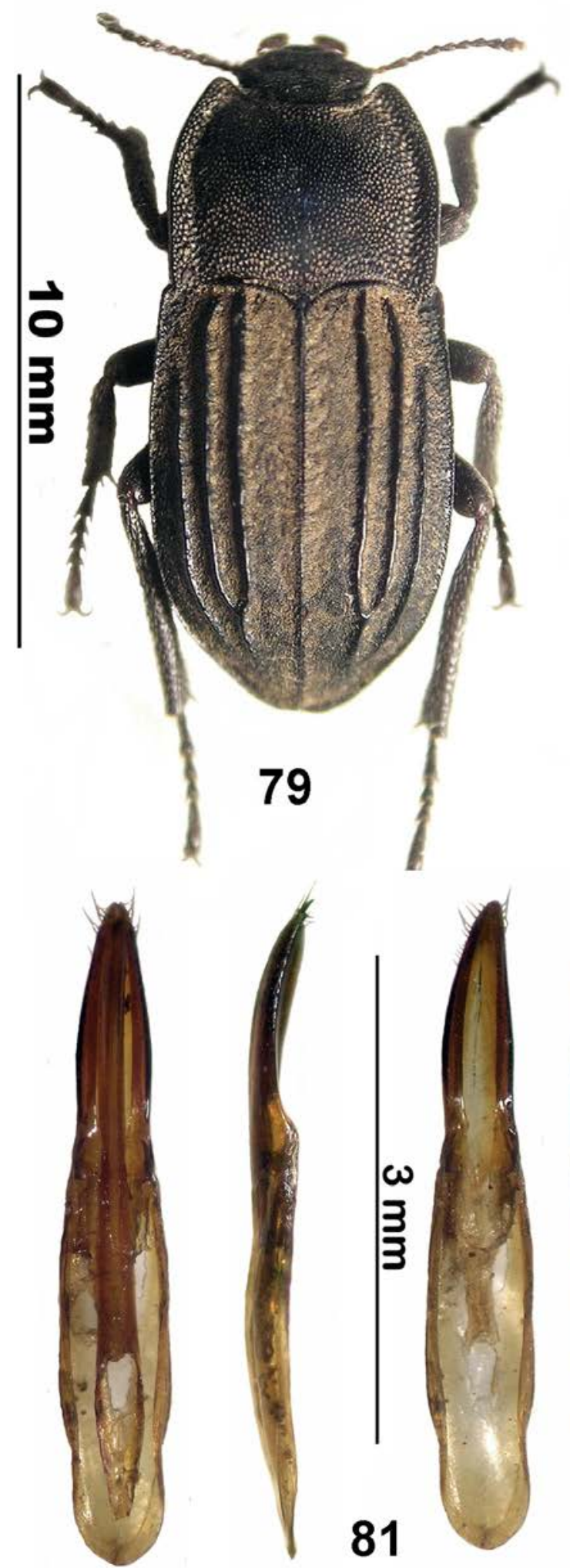

ventriapicalis y en el centro del area intercoxitalis; el area basalis poco profunda y lisa. El scleritus vulvaris medianus normalmente esclerotizado.

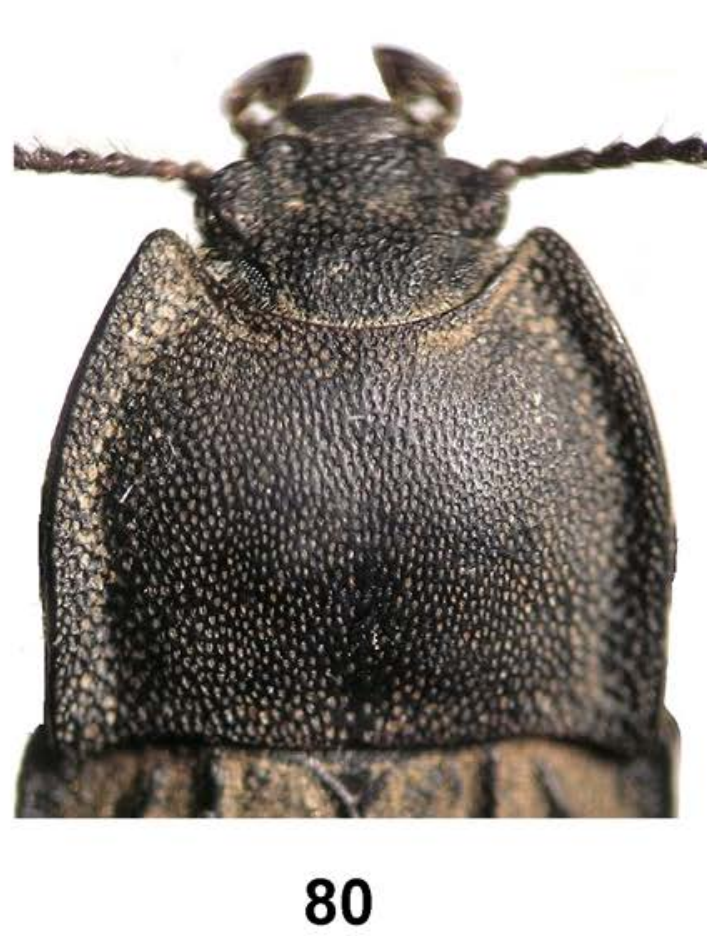

Figs. 79-82.- Alphasida (Elongasida) tenuecostata (Fairmaire, 1880): 79, habitus del Lectotipo $\widehat{\jmath}$ (MNHN); 80, pronoto; 81, edeago, vistas dorsal y lateral y vista dorsal de la pieza principal y del endofalo; 82, élitro.

Figs. 79-82.- Alphasida (Elongasida) tenuecostata (Fairmaire, 1880): 79. Habitus of the $\sigma^{1}$ Lectotypus (MNHN); 80, pronotum; 81 , dorsal and side views of aedeagus and dorsal view of principal piece and endophallus; 82, left elytra. 
DistRIBUCIÓN GEOGRÁFICA.- La especie se distribuye por la región de Ksar el Kbir a unos $30 \mathrm{~km}$ al sureste de Larache, en las localidades de Arbaoua y Lalla Mimouna.

\section{Alphasida (Elongasida) tenuecostata (Fairmaire, 1880) (figs. 79-82) \\ Asida tenuecostata Fairmaire, 1880a: 190 \\ Alphasida (Pseudoelongasida) tenuecostata (Fairmaire): Pérez- Vera, 2012: 125 \\ Locus TYPICUS.- Fez (Marruecos).}

Tipo eXAminado.- 10 Lectotypus, $A$. tenuecostata (escritura de Fairmaire) [etiqueta blanca manuscrita]; Fez [etiqueta blanca manuscrita]; Syntype [etiqueta roja impresa]; Lectotypus Asida tenuecostata Fairmaire. Pérez-Vera des. 2011 [etiqueta roja impresa] (MNHN).

Complementos DE DESCRIPCiÓN.- La descripción detallada del macho (fig. 79) pone en evidencia las características diferenciales más notables con la especie silvestrei, muy próxima (Pérez-Vera, 2012: 127). Ellas se sitúan a nivel del pronoto (fig. 80), que es muy poco transverso, con los ángulos anteriores muy salientes hacia delante, las márgenes estrechas y de bordes levantados; los élitros (fig. 82) con la base discretamente más ancha que la del protórax, de silueta un poco más oblonga, más acuminados en la extremidad y con una declividad posterior muy débil. Tanto los élitros como el pronoto presentan una cortísima pilosidad clara algo rojiza, muy caduca, pero aún observable a gran aumento, que no fue señalada en ningún momento por Fairmaire en sus descripciones originales.

El edeago (fig. 81) de índice $\mathrm{Ph} / \mathrm{Pa}=1,25$ con la ojiva parameral ligeramente estrechada tras los tubérculos dorsales; el endofalo discretamente aplastado a la base y progresivamente afilado en su mitad distal hasta el ápex.

Comentarios.- Cuando la especie fue descrita, Fairmaire disponía de más ejemplares aparte del único, recuperado hoy, puesto que hizo mención de los caracteres de las hembras. Por ello creemos que una investigación más profunda debería realizarse en los 'magasins' de Oberthür del MNHN de Paris y en las amplias colectas de Schramm conservadas en el Institut Scientifique de Rabat.

DistriBución GEOGRÁfiCA.- Parece estar limitada a los alrededores de Fez (Marruecos).

\section{Agradecimientos}

Éste trabajo ha podido realizarse por la importante ayuda de las Dras. Mercedes París y Amparo Blay, responsables de la Colección de Entomología del MNCN de Madrid, que nos han acogido con la amabilidad y la amistad que les caracterizan durante todas nuestras visitas al Museo, nos han proporcionado toda la información indispensable y han puesto a nuestra disposición el material y los medios de estudio necesarios, confiándonos igualmente los numerosos ejemplares históricos que se guardan en las colecciones de su institución. También queremos agradecer la amable colaboración del Dr. Antoine Mantilleri, Conservador de las colecciones entomológicas del MNHN que nos ha acogido cordialmente durante nuestra reciente visita a dicha entidad y a nuestros amigos y colegas que nos han cedido materiales para estudio, José Luis Lencina (Jumilla, Murcia) y José Fermín Sánchez (San Pedro del Pinatar, Murcia).

\section{Referencias}

Allard, E., 1869. Révision du genre Asida (Latr.). L'Abeille, Journal d'Entomologie, 6: 159-304.

Escalera, M. M. de la, 1906. Sistema de las especies ibéricas del gen. Asida Latr. Boletín de la Real Sociedad Española de Historia Natural, 6: 306-317.

Escalera, M. M. de la, 1921. Descripciones de especies nuevas de Asida de la Península Ibérica. Boletín de la Real Sociedad Española de Historia Natural, 21: 117-120.

Escalera, M. M. de la, 1922. Especies nuevas de Asida de Marruecos. Boletín de la Real Sociedad Española de Historia Natural, 22: 170-175.

Fairmaire, L., 1880a. Diagnoses de coléoptères du Maroc. Le Naturaliste, 2: 190.

Fairmaire, L., 1880b. Descriptions des coléoptères nouveaux du nord de l'Afrique. 4e partie. Annales de la Société Entomologique de France, 10: 245-254.

Fleming, J., 1821. Insecta. In: Supplement to the Fourth, Fifth and Sixth Editions of the Encyclopaedia Britannica. Volume Fifth [Part 1]. 584 pp. A. Constable and Company. Edinburgh: 41-56, pl. 85.

ICZN, 1999. International Code of Zoological Nomenclature. 4th Edition. The International Trust for Zoological Nomenclature. London. xxix +306 p.

Latreille, P. A., 1802. Histoire naturelle, générale et particulière des crustacés et des insectes. Ouvrage faisant suite aux cuvres de Leclerc de Buffon et partie du cours complet d'Histoire naturelle rédigé par C. S. Sonnini, membre de plusieurs sociétés savantes. Familles naturelles des genres. Tome troisième. F. Dufart. Paris. xii + $13-467+[1] \mathrm{pp}$.

Martínez y Sáez, F., 1873. Descripciones de coleópteros de España. Anales de la Sociedad Española de Historia Natural, 2: 407-417.

Pérez Arcas, L., 1865. Insectos nuevos o poco conocidos de la fauna española. Segunda parte. Revista de los Progresos de las Ciencias Exactas, Físicas y Naturales, 15: 413-444.

Pérez-Vera, F., 2012. Les Asidini marocains VII. Le sousgenre Pseudoelongasida Escalera, 1922. Désignation d'un lectotype pour Asida tenuecostata Fairmaire, 1880 (Coleoptera, Tenebrionidae). Bulletin de la Société Entomologique de France, 117(1): 123-129. 
Pérez-Vera, F., 2014. L'ovipositeur et sa signification dans la taxonomie de la tribu des Asidini (Coleoptera, Tenebrionidae). Bulletin de la Société entomologique de France, 119(2): 181-190.

Pérez-Vera, F. \& Ávila, J. M., 2012a. Asidini Marroquíes VI. Descripción de tres nuevas especies pertenecientes al género Alphasida Escalera, 1905 y de una subespecie nueva del género Asida Latreille, 1802 (Coleoptera, Tenebrionidae). Graellsia, 68(1): 17-29. http://dx.doi. org/10.3989/graellsia.2012.v68.047

Pérez-Vera, F. \& Ávila, J. M., 2012b. Presentación de un ensayo monográfico sobre la tribu Asidini en Marruecos (Coleoptera, Tenebrionidae, Pimeliinae). Boletín de la Sociedad Entomológica Aragonesa, 51: 295-299.

Pérez-Vera, F. \& Ávila, J. M., 2012c. Los Asidini marroquíes. Ensayo monográfico sobre la tribu Asidini (Coleoptera, Tenebrionidae) en el Reino de Marruecos. Monografías electrónicas SEA n ${ }^{\circ}$ 3. Sociedad Entomológica Aragonesa. Zaragoza. 203 pp. CXXXIII pl. Disponible en http://sea-entomologia.org/monoelec.html

Pérez-Vera, F. \& Ávila, J. M., 2016. Sur le statut taxonomique d'Asida asperata Solier, 1836, et la synonymie avec A. squalida Allard, 1869 (Coleoptera, Tenebrionidae,
Asidini). Bulletin de la Société entomologique de France, 121(1): 119-122.

Pérez-Vera, F. \& Ávila, J. M., 2017. Révision des Alphasida (Glabrasida) Escalera, 1910, groupe II (sous-genre Pedarasida Reitter, 1917, part.) (Coleoptera, Tenebrionidae, Asidini). Bulletin de la Société entomologique de France, 122(3): 367-400.

Rambur, J. P., 1838. Fauna Entomologique de l'Andalousie. Vol. I. Arthus Bertrand. Paris. 144 pp., pls I, II, XIX, XX.

Reitter, E., 1917. Bestimmungs-Tabelle der palaearctischen Arten der Tenebriniden-Abteilung Asidini. Verhandlungen des Naturforschenden Vereins in Brünn, 55: 1-74.

Soldati, F., 2008. Asidini. In: I. Löbl \& A. Smetana (eds.). Catalogue of Palaearctic Coleoptera, Vol. 5. Apollo Books. Stenstrup: 128-139.

Solier, A. J. J., 1836. Essai sur les collaptèrides. 6e Tribu. Asidites. Annales de la Société Entomologique de France, [1835-1836], 5: 403-512, pls. XI-XIII.

Viñolas, A. \& Cartagena, M. C., 2005. Fauna de Tenebrionidae de la Península Ibérica y Baleares. Vol. 1. Lagriinae y Pimeliinae. Argania editio. Barcelona. 428 pp. 